\title{
A REVIEW OF FORMULATIONS TO DESIGN AN ADHESIVE SINGLE-LAP JOINT FOR USE IN MARINE APPLICATIONS
}

UDC 621.791.052.2

Review paper

\begin{abstract}
Summary
The single adhesive joint has many applications in the shipbuilding industry, where it offers the advantage of joining materials (adherents) with different properties and characteristics using an adhesive. However, one disadvantage of this type of joint is the stress concentration at the ends of the joint, which directly affect the adhesive. Another disadvantage is the possible difference between the coefficients of thermal expansion of the adherents of the joint. Through compilation and classification of the formulas found in various publications, this study presents a state-of-the-art review of an adhesive single-lap joint that can be used in marine applications. It will consider the types of materials used as the adhesive and as the adherents, the possibility of varying the thicknesses of the adherents and the thickness of the adhesive, and the recommended design factors for each proposed methodology. This study proposes formulas to estimate the stresses for joints with balanced thicknesses and extrapolates the results for nonbalanced joints; also, an equation is derived to calculate the minimum overlap joint length for ship lengthening, allowing the design process to be simplified. The results are expected to facilitate the design of single-lap joints in marine applications, such as reinforcing composite panels and lengthening of hulls and superstructures.
\end{abstract}

Keywords: $\quad$ single-lap joint; adhesives; adherents; shear stress; normal stress; interlaminar strength; shipbuilding

\section{Introduction}

The need to produce adhesive joints between two materials with the same or different characteristics has led to multiple investigations into developing equations that allow estimating the stresses in single-lap joints. Single-lap joints can be observed in different applications in the marine industry using composite material, such as the following examples:

- Dominguez [1] made a review of the state of the art presenting different hybrid joints between a steel deck and an FRP (fibre reinforced polymers) superstructure of various sizes. Hybrid adhesive bonding has also been applied by the Kockums shipyard on commercial vessels and military ships. 
- In the welding of a fibre reinforced polymers (FRP) beam or the reinforcement of an FRP composite panel, or in a hybrid joint when fixing a metal reinforcement to an FRP composite panel, [1]-[3], as presented in Fig. 1. In these examples, the FRP stiffener laminate is considered the top adherent, the inferior FRP sandwich panel is the bottom adherent, and the polyester resin is the adhesive.

- In the lengthening of FRP hull or superstructure of a vessel, whereby a single-lap joint must be made, which can be balanced or non-balanced joint, as indicated in Fig. 2.
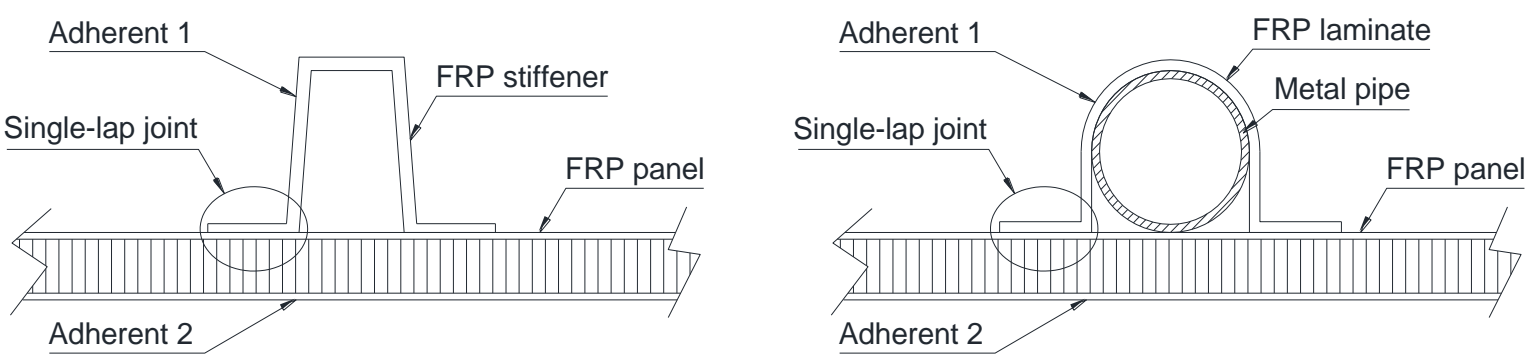

Fig. 1: Adhesive joint between FRP laminate and FRP stiffener

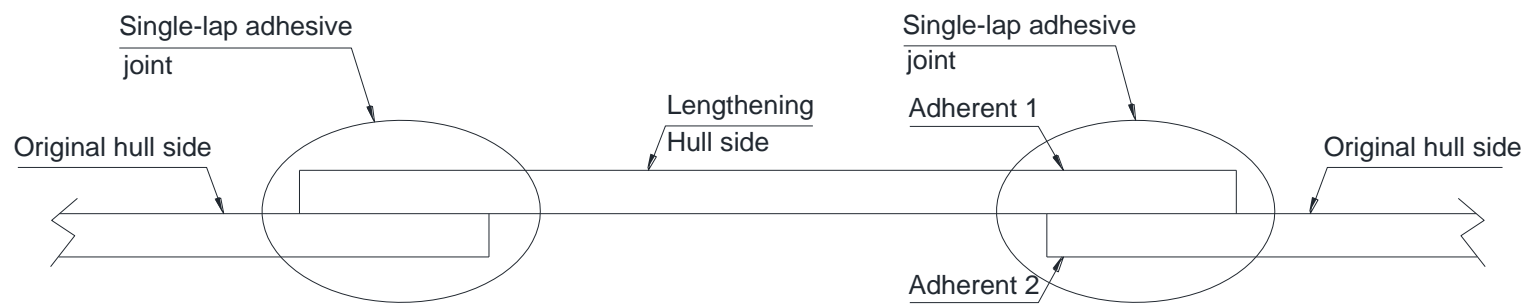

Fig. 2: Hull shell lengthening of an FRP ship

The adherent materials in these adhesive joints can be steel, stainless steel, aluminium, FRP composite laminate, carbon fibre reinforced polymer (CFRP), bio-composite [4], or a combination of these.

To perform comprehensive literature, we reviewed several types of research, and abstracting databases published from 1938 to 2019 were initially considered. Only peerreviewed journal articles with novel contributions to the field were critically reviewed.

The first research on single-lap joints was undertaken by Volkersen [5] in 1938. Since then, several authors have continued to improve and propose new methodologies for estimating the shear and normal stresses in the adhesive. Successive investigations have been developed considering the adherents as isotropic, orthotropic, or anisotropic, or considering the adhesive as isotropic. The stress-strain curve is approximated in a linear or non-linear manner, and the resulting stress formulas in the adhesive can be explicit or implicit.

This document aims to review the methods developed and proposed for the analysis of single-lap joints, thereby allowing the reader to select the methodology that is most convenient for the marine application at hand. Table 1 presents a classification of these joints based on their configuration, mathematical model and formulas proposed by each author. Later, an analysis of each mentioned formulation and the involved variable is conducted to provide a general approach for selecting a single adhesive joint. 


\section{Summary of the reviewed studies of adhesive single-lap joints}

\subsection{State of the art}

This research compiles the most cited investigations that have contributed to the development of the analysis of single adhesive joints. Volkersen [5] and Goland and Reissner [6] were the first to analyse this type of joint, and their assumptions are still taken as a comparative reference in new researches.

Table 1 summarizes the classification of the proposed methods by the different authors based on the main considerations of a single-lap joint:

Table 1 Summary of calculation methods for a single adhesive joint (*); Clark [7].

\begin{tabular}{|c|c|c|c|c|c|c|c|c|c|c|c|c|c|c|}
\hline Year & Author & 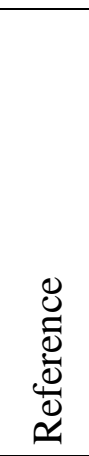 & 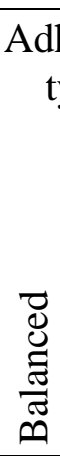 & 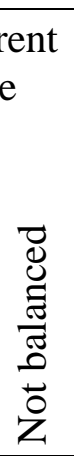 & $\begin{array}{c}0 \\
.0 \\
0 \\
0 \\
0 \\
0 \\
0\end{array}$ & 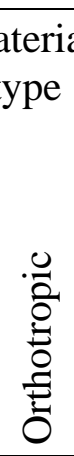 & $\begin{array}{c}\cdot 0 \\
0 \\
0 \\
0 \\
0 \\
.0 \\
\vdots \\
\vdots\end{array}$ & 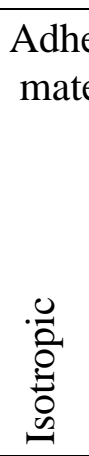 & 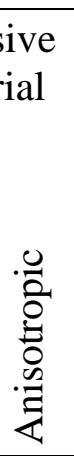 & 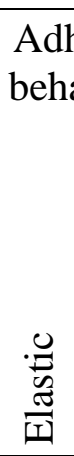 & $\begin{array}{l}.0 \\
\frac{0}{0} \\
\frac{\pi}{2}\end{array}$ & $\underset{\Xi}{. \beth}$ & 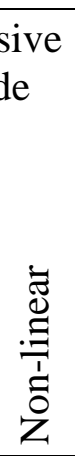 & 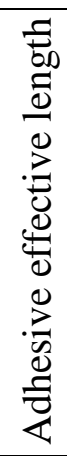 \\
\hline \multicolumn{15}{|c|}{ Methods with the explicit formulation } \\
\hline \multirow{2}{*}{$\begin{array}{l}1938 \\
1944\end{array}$} & Volkersen & [5] & $\mathrm{x}$ & & $\mathrm{x}$ & & & $\mathrm{x}$ & & $\mathrm{x}$ & & $\mathrm{x}$ & & \\
\hline & $\begin{array}{l}\text { Goland } \\
\text { and } \\
\text { Reissner }\end{array}$ & {$[6]$} & $\mathrm{x}$ & & $\mathrm{x}$ & & & $\mathrm{x}$ & & $\mathrm{x}$ & & $\mathrm{x}$ & & $\mathrm{x}^{(*)}$ \\
\hline \multirow{3}{*}{$\begin{array}{l}1973 \\
1977 \\
1989\end{array}$} & Hart Smith & {$[8]$} & $\mathrm{x}$ & $\mathrm{x}$ & $\mathrm{x}$ & & & $\mathrm{x}$ & & $\mathrm{x}$ & $\mathrm{x}$ & $\mathrm{x}$ & $\mathrm{x}$ & \\
\hline & Allman & [9] & $\mathrm{x}$ & & $\mathrm{x}$ & & & $\mathrm{x}$ & & $\mathrm{x}$ & & $\mathrm{x}$ & & \\
\hline & $\begin{array}{l}\text { Bigwood } \\
\text { and } \\
\text { Crocombe }\end{array}$ & {$[10]$} & $\mathrm{x}$ & $\mathrm{x}$ & $\mathrm{x}$ & & & $\mathrm{x}$ & & $\mathrm{X}$ & & $\mathrm{x}$ & & \\
\hline 1991 & Oplinger & {$[11]$} & $\mathrm{x}$ & $\mathrm{x}$ & $\mathrm{x}$ & & & $\mathrm{x}$ & & $\mathrm{x}$ & & $\mathrm{x}$ & & $\mathrm{x}$ \\
\hline 2004 & Zou & [12] & $\mathrm{x}$ & & $\mathrm{x}$ & & & $\mathrm{x}$ & & $\mathrm{x}$ & & $\mathrm{x}$ & & \\
\hline \multicolumn{15}{|c|}{ Methods with the implicit formulation } \\
\hline 1973 & $\begin{array}{l}\text { Renton and } \\
\text { Vinson }\end{array}$ & {$[13]$} & $\mathrm{x}$ & $\mathrm{x}$ & $\mathrm{x}$ & $\mathrm{x}$ & $\mathrm{x}$ & $\mathrm{x}$ & & $\mathrm{x}$ & & $\mathrm{x}$ & & $\mathrm{x}$ \\
\hline 1977 & Ojalvo & [14] & $\mathrm{x}$ & & $\mathrm{x}$ & & & $\mathrm{x}$ & & $\mathrm{x}$ & & $\mathrm{x}$ & & \\
\hline 1981 & Delale & [15] & $\mathrm{x}$ & & $\mathrm{x}$ & $\mathrm{x}$ & & $\mathrm{x}$ & & $\mathrm{x}$ & & $\mathrm{x}$ & & \\
\hline 1992 & $\begin{array}{l}\text { Adams and } \\
\text { Mallick }\end{array}$ & [16] & $\mathrm{x}$ & $\mathrm{X}$ & & & $\mathrm{x}$ & $\mathrm{x}$ & & $\mathrm{x}$ & & $\mathrm{x}$ & $\mathrm{x}$ & \\
\hline 1996 & Tong & [17] & $\mathrm{x}$ & & $\mathrm{x}$ & & & $\mathrm{x}$ & & $\mathrm{x}$ & & $\mathrm{x}$ & $\mathrm{X}$ & \\
\hline 2003 & Smeltzer & [18] & $\mathrm{x}$ & $\mathrm{x}$ & & & $\mathrm{x}$ & $\mathrm{x}$ & $\mathrm{x}$ & $\mathrm{x}$ & $\mathrm{x}$ & $\mathrm{x}$ & $\mathrm{X}$ & \\
\hline
\end{tabular}

The comparative analysis undertaken in this review accounts for the aspects presented in Table 2 to make the proposed methodologies more comprehensive. 
Table 2 Description of the specific aspects of the methods for producing single-lap joints.

\begin{tabular}{|c|c|c|}
\hline ASPECTS & TYPE & DESCRIPTION \\
\hline \multirow[t]{2}{*}{$\begin{array}{l}\text { Method } \\
\text { formulation }\end{array}$} & Explicit & $\begin{array}{l}\text { The method develops a closed solution; that is, the authors } \\
\text { provide formulas of stresses that can be directly evaluated. }\end{array}$ \\
\hline & Implicit & $\begin{array}{l}\text { The method is not fully developed; that is, the authors } \\
\text { express the formulas or require numerical analysis or } \\
\text { implementation of additional programs to apply the } \\
\text { method. }\end{array}$ \\
\hline \multirow[t]{2}{*}{ Adherent type } & Balanced & $\begin{array}{l}\text { The upper and lower adherents are of equal thickness and } \\
\text { mechanical properties. }\end{array}$ \\
\hline & $\begin{array}{l}\text { Non- } \\
\text { balanced }\end{array}$ & $\begin{array}{l}\text { The upper and lower adherents are of different thicknesses } \\
\text { or different mechanical properties. }\end{array}$ \\
\hline \multirow{3}{*}{$\begin{array}{l}\text { The material of } \\
\text { adherent and } \\
\text { adhesive }\end{array}$} & Isotropic & $\begin{array}{l}\text { The method considers the adherent or adhesive as a material } \\
\text { that retains the same properties in all directions. }\end{array}$ \\
\hline & Orthotropic & $\begin{array}{l}\text { The method considers uses the adherent or adhesive as a } \\
\text { material that has defined properties in three directions. }\end{array}$ \\
\hline & Anisotropic & $\begin{array}{l}\text { The method considers the adherent or adhesive as a material } \\
\text { that has defined properties in all directions. }\end{array}$ \\
\hline \multirow[t]{2}{*}{$\begin{array}{l}\text { Adhesive } \\
\text { behaviour }\end{array}$} & Elastic & $\begin{array}{l}\text { For the stress analysis, the adhesive deformation is } \\
\text { maintained in the elastic zone of the stress-strain curve. }\end{array}$ \\
\hline & Plastic & $\begin{array}{l}\text { For the stress analysis, the adhesive deformation is } \\
\text { maintained in the plastic zone of the stress-strain curve. }\end{array}$ \\
\hline \multirow[t]{2}{*}{ Adhesive model } & Lineal & $\begin{array}{l}\text { The methodology considers the linear behaviour of the } \\
\text { adhesive for its mathematical approach and stress } \\
\text { estimation. }\end{array}$ \\
\hline & Non-lineal & $\begin{array}{l}\text { The methodology considers the non-linear behaviour of the } \\
\text { adhesive for its mathematical approach, variables, and } \\
\text { assumptions. }\end{array}$ \\
\hline \multicolumn{2}{|c|}{ Adhesive effective length } & $\begin{array}{l}\text { Each author proposes a formula to estimate or recommend } \\
\text { the length of the adhesive for the single-lap joint geometry. }\end{array}$ \\
\hline
\end{tabular}

2.2. Configuration of the adhesive joint

\subsubsection{Type of joint}

In Fig. 3, the following four configurations for single-lap joints are shown:

- Option a: Classic joint with orthogonal vertices at the ends of the adherents and the adhesive.

- Option b: Joint with rounded vertices at the ends of the adherents and orthogonal at the ends of the adhesive.

- Option c: Joint with short bevelled vertices at the ends of the adherents and orthogonal at the ends of the adhesive.

- Option d: Joint with long bevelled vertices at the ends of the adherents and orthogonal at the ends of the adhesive.

Option a is typically used in most single adhesive joints. This option is described in the methods listed in section 2.3. 
Options $\mathrm{b}$ and $\mathrm{c}$ allow the reduction of the maximum shear and normal stresses generated at the ends of the adhesive, but their mathematical development is complex; therefore, the finite element analysis (FEA) is recommended for designing this type of joint (Calik [19]).
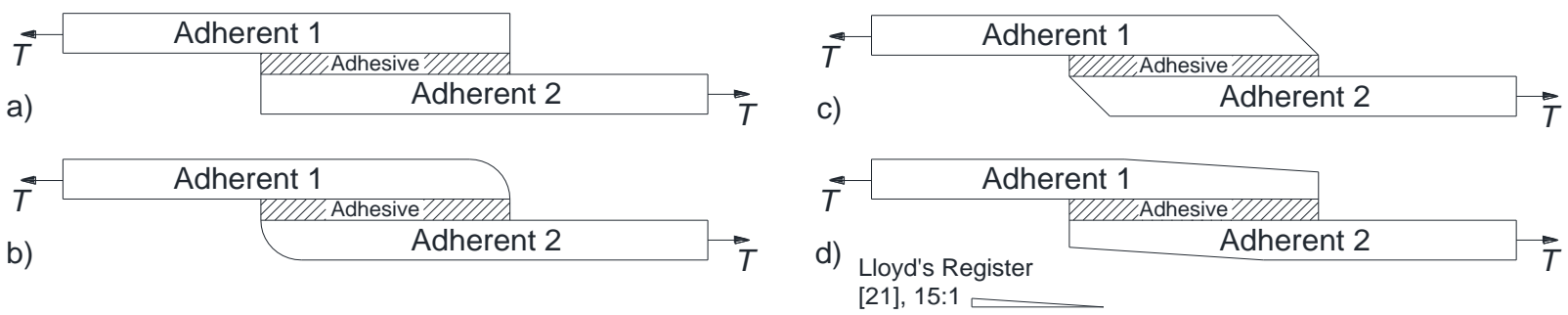

Fig. 3: Adhesive single-lap joint types

Option $\mathrm{d}$ is mostly used for the adherents of composite materials with staggered laminate layers at the ends of the adherents. Oterkus [20] investigated this type of overlapping joint, proposing a semi-analytical method taking into account the linear and bilinear elastic behaviour of the adhesive and the linear behaviour of the adherents. As a result of this analysis, he obtained a system of non-linear equations for shear and normal stresses, to be solved by an iterative procedure using the Newton Raphson method together with Broyden's Jacobian matrix [20].

Fig. 4 shows Oterkus's [20] results, whereby it is observed that the shear and normal stresses decrease with the increase in the size of the bevel on the adherent ends. For this case, Lloyd's Register recommends using staggered bevels, as shown in Fig. 8.
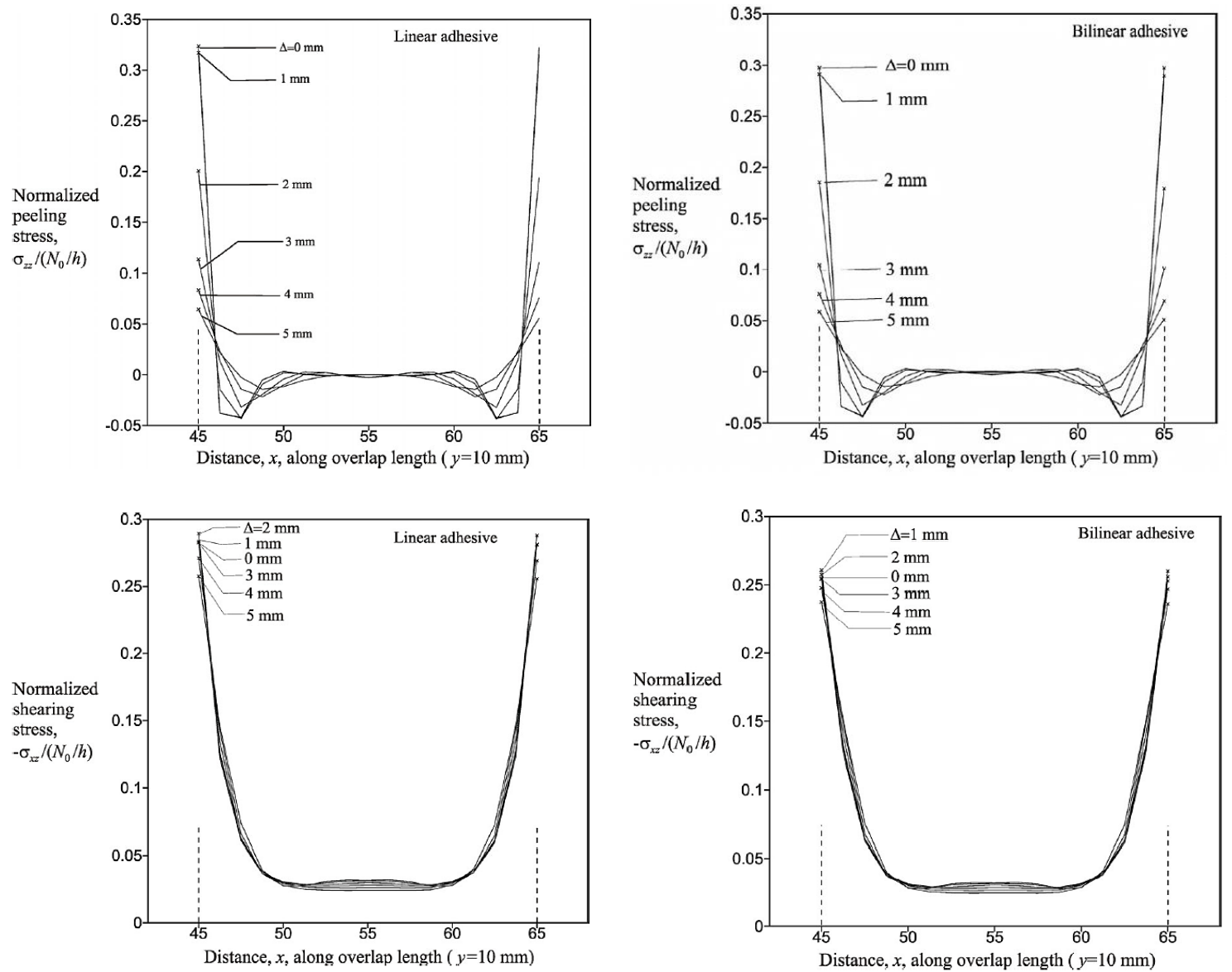

Fig. 4: Stress results, based on the linear and bilinear behaviour of the adhesive; Oterkus [20] 


\subsubsection{Materials}

The materials used in a single-lap joint can vary depending on the intended application. In the case of composite materials, adherents can be considered as isotropic, orthotropic or anisotropic materials, depending on the methodology applied for the analysis.

\subsubsection{Adherents}

The materials, and their combinations, that have been used as adherents are presented in Table 3.

Table 3 Materials used in single-lap joints.

\begin{tabular}{lll}
\hline Metals & Composites & Combined Materials \\
\hline Steel & Fibre-reinforced polymers, FRP & Steel/fibreglass laminate \\
Aluminium & Carbon fibre reinforced polymers, CFRP & Steel/carbon fibre laminate \\
Stainless & & Aluminium/fibreglass laminate \\
steel & & \\
& & Aluminium/carbon fibre laminate \\
\hline
\end{tabular}

Metals are common adherents, and their mechanical properties depend on the type of alloy used. For composite materials, the properties depend on the type of resin (polyester, vinyl ester, or epoxy) and the type of fibre used. Composite materials can be grouped as orthotropic or anisotropic [13] [18] based on their laminate; however, in the explicit methods, adherents are considered isotropic.

In adhesive lap joints where the adherents are considered metallic, the first failure is expected to be generated in the adhesive and then in the adherent. Meanwhile, for joints with laminated composite adherents, the first failure is expected to appear in the adherent [8]; see Fig. 5.

In the case of a joint between FRP composite materials as the adherents with polyester resin as the adhesive, the behaviour of the stress-strain curve of the adherents must be taken into account because after the elastic deformation, the joint will present a failure by delamination [21].

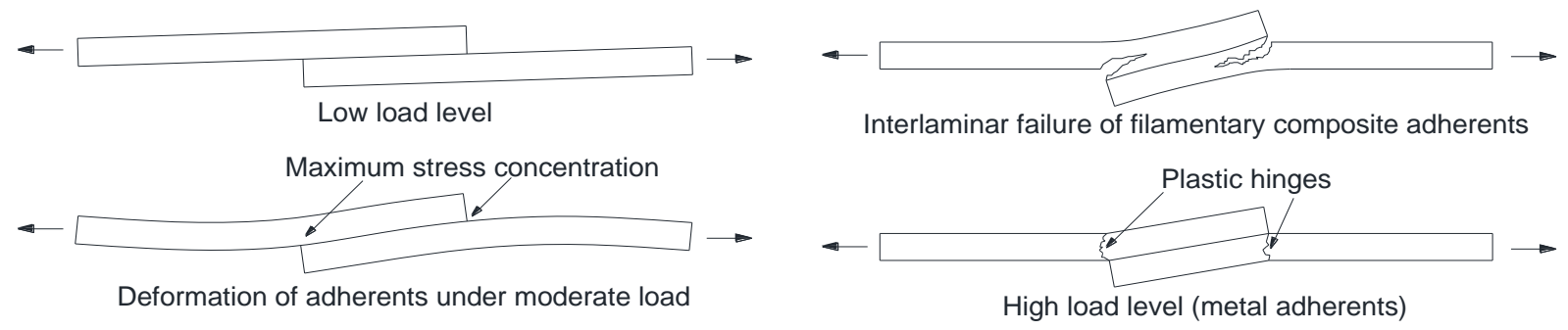

Fig. 5: Possible failures of a single-lap joint; Hart-Smith [8]

\subsubsection{Adhesives}

In most of the investigated methods for the single-lap joint, the behaviour of the adhesive is approximated as isotropic-elastic. Banea [22] presented a table summarizing the typical properties of the different types of adhesives, which include the epoxy type, anaerobic or silicone type, and polyurethane type, among others. 
Hart-Smith [8][23]-[26] emphasized the importance of including, in the calculations, the estimation of the stresses obtained in the plastic area of the adhesive. The typical stress-strain behaviour of an adhesive and the equivalent linear and bilinear curves are presented in Fig. 6 . The hatched sections correspond to the proposed method to find the equivalence between the energy density of the typical nonlinear characteristic curve and the linear or bilinear curve. Hart-Smith [23] concluded that the complexity of the bilinear representation of the adhesive leads to fairly approximate results when compared to the results obtained with the linear estimation, provided that the same equivalent adhesive energy density curve is maintained.

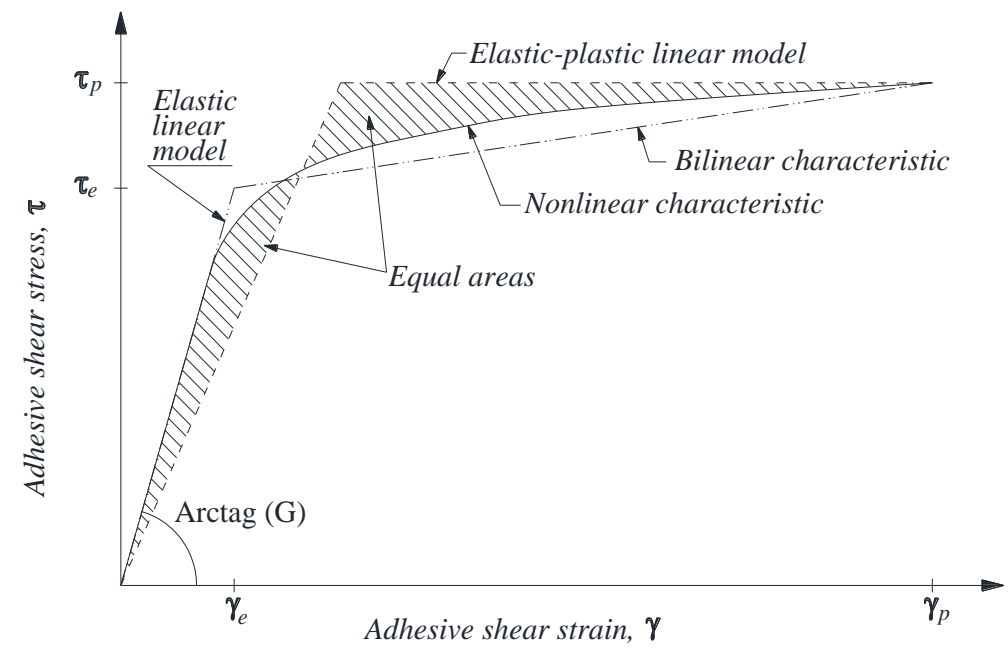

Fig. 6: Typical representation of the equivalence between the characteristics of the adhesive; Hart-Smith [26]

Fig. 7 shows an example of the distribution of shear and normal stresses in the adhesive, considering elastic-plastic behaviour, whereby it is observed that the length of the adhesive is divided into three sections: a central elastic zone and two plastic zones at either end. This detail is important because the larger the plastic zone, the greater the possibility of normal stress increase, which may lead to cracking in the adhesive.
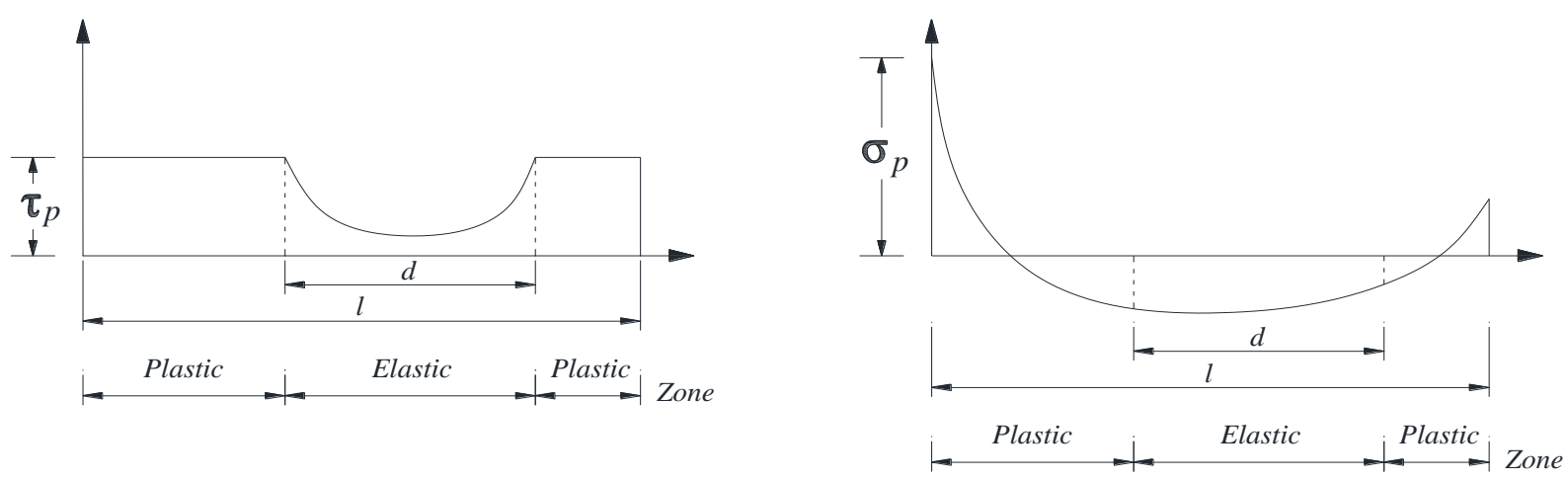

Fig. 7: Distribution of stresses in the adhesive, elastic and plastic zones; Hart-Smith [23]

For length $l$ where the adhesive is considered perfectly plastic $(d=0)$, it is true that $\tau_{\text {avg }}=\tau_{p}$. Hart-Smith [8] recommended considering the following: 
Franklin Dominguez

Luis Carral
A review of formulations to design an adhesive single-lap joint for use in marine applications

$$
l \leq \frac{1}{\lambda} \cdot \sqrt{\frac{4 \cdot\left(\frac{2 \cdot \gamma_{e}}{\gamma_{p}}\right)}{1+\frac{3 \cdot k \cdot\left(1-v^{2}\right)}{k_{b}} \cdot\left(1+\frac{n}{t}\right)}}
$$

The formulas for estimating the length of the adhesive are explained in section 2.4.1

\subsection{Considerations for modelling joint behaviour}

Volkersen [5] investigated the behaviour of the single-lap joint, in which the balanced adherents and the adhesive were considered as elastic and isotropic materials. This investigation did not consider deformations in the adherents or bending moments in the adhesive joint generated by eccentricity. The linear mathematical model initially proposed by Volkersen [5] only considered the shear force on the adhesive, with maximum values at its ends and a minimum at the halfway point.

Goland and Reissner [6] developed formulas to estimate the shear and the normal stresses of an adhesive single-lap joint. They considered that the deformations that occur in the adherents are relatively small in comparison to the deformations produced in the adhesive. Besides, the deformations in the adherents are due to the cylindrical flexion generated by the flexural moment that is formed by the eccentricity of the applied load. Adherents and adhesives are considered perfectly elastic. This study resulted in a linear method that applies only for adhesives with thin thicknesses as well as for balanced joints, that is, those with the same geometry and properties.

Hart-Smith [8] analysed a single-lap joint considering the behaviour of both linear-elastic and plastic adhesives. The plastic zone of the adhesive bond is considered for the range $(l-d)$; see Fig A.3. With this assumption, Hart-Smith validated the theoretical results with the experimental results. Furthermore, this analysis found that maximum shear and normal stresses occur at the ends of the adhesive joint, while the lowest stresses occur in the middle, concluding that an exaggerated increase in the length of the adhesive bond does not reduce stress because the load is processed along an effective length.

Allman [9] based his investigation on research by Goland and Reissner [6] that considered the elastic linear behaviour of an adhesive on a balanced joint. This author proposed estimating the stresses based on the non-deformable geometry of the single-lap joint and considering the adherents and the adhesive as isotropic materials, allowing both metallic and composite adherents to be analysed. This method assumes that the shear stresses do not vary across the thickness of the adhesive, while the normal stresses vary.

Bigwood and Crocombe [10] investigated the shear and normal stress estimation of a single-lap joint considering the adhesive as elastic-linear. For their mathematical analysis, they considered the length of the adhesive and its ends subjected to tensile, shear, and moment loads; see Fig. A.6. The adherents and adhesives were considered as isotropic material, and the adherents could be unbalanced.

Oplinger [11] [27] proposed formulas to estimate the stresses of the single-lap joint. Like other authors, Oplinger based this work on that of Goland and Reissner [6], but in these formulas, the adherents work independently (upper and lower). Adherents and adhesives were analysed as an elastic isotropic material. This methodology allows the estimation of the shear and normal stresses for adherents with thin thicknesses. Oplinger [11] obtained similar results to those of Goland and Reissner [6] for thick adherents; however, greater differences were found in the estimations for thin adherent thicknesses. 
Lastly, Zou [12], when analysing the single-lap joint, defined the adhesive as having homogeneous, isotropic, and linear elastic behaviour and stated that the adherents must be balanced.

The listed explicit and the implicit methods in Table 1 are published formulas to calculate the adhesive stresses on single-lap joints; other papers are dedicated to validate these methods with FEA or experimentation.

\subsection{Summary of formulas}

\subsubsection{Adhesive length}

Clark [7], taking as reference the formulas proposed by Goland and Reissner [6], recommended an adhesive length based on the parameter $\beta / t$, adhesive shear stress $\tau_{a}$ and average adherent stress $\tau_{\text {avg }}$.

Renton and Vinson [13] recommended estimating the length of the adhesive using the approximate ratio of $1 / t=10$. If this relationship is greater than 10 , failures in the adherent are expected; however, if this ratio is less than 10, failure in the adhesive is expected.

Oplinger [27] proposed a detailed formula based on geometric and mechanical properties, using the parameters $\lambda$ and $\Lambda$.

Table 4 Adhesive effective length formulas.

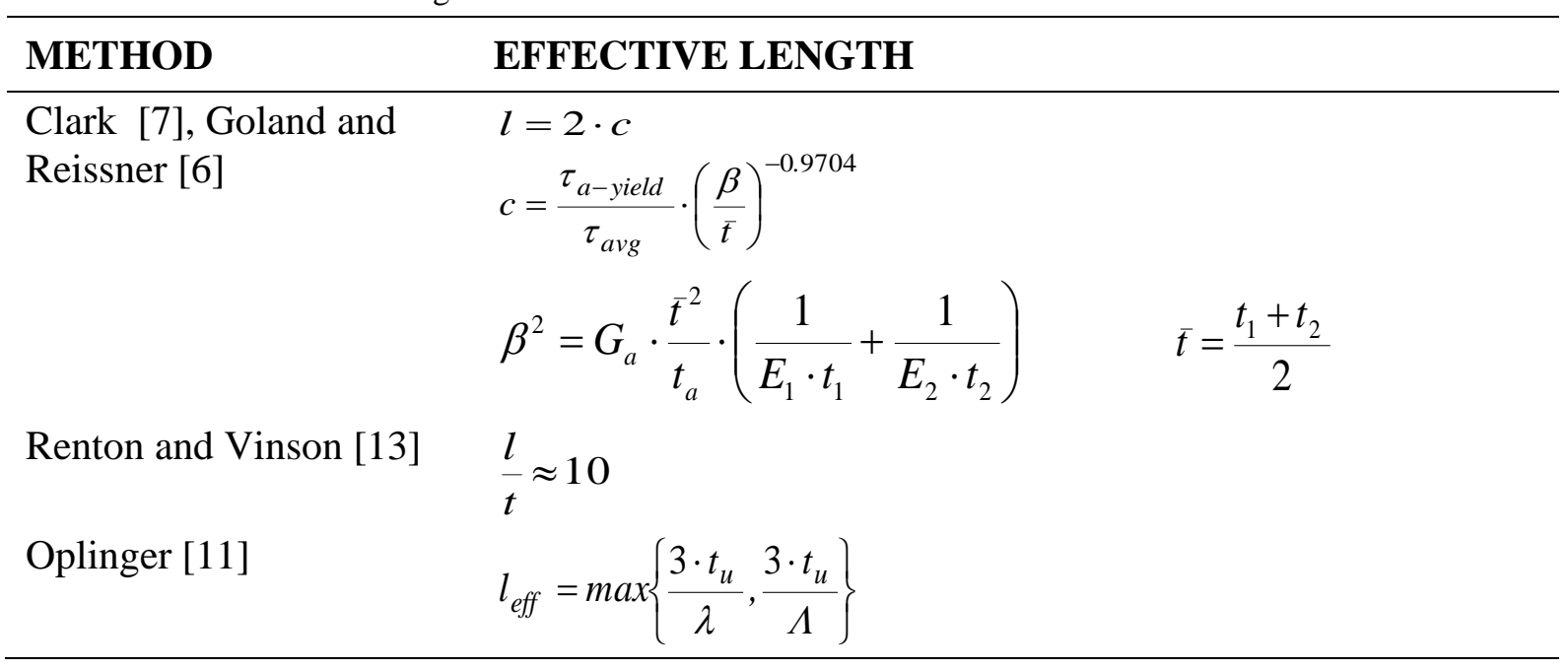

The variables in Table 4 are indicated in the appendix.

\subsubsection{Moment due to the eccentricity of the adherents}

In the single-lap joint, applying a load to the adherents generates a moment of eccentricity between the axis of the adhesive and the axis of the applied load [6][8][11]. This moment then generates deformations in the adhesive and the adherent as well as shear and normal stresses. Due to the condition of the single-lap joint for the estimation of the normal and shear stresses in the adhesive, the moment generated by the adherent must be multiplied by the eccentricity factor $k$.

Goland and Reissner [6] were the first to estimate the eccentricity factor k for a balanced joint involving the properties of isotropic adherents, such as thickness, elasticity modulus, Poisson number and applied load. Their proposed moment is: 


$$
M_{0}=k \cdot \frac{P \cdot t}{2} \cdot\left(1+\frac{t_{a}}{t}\right)
$$

Hart-Smith [8] retained the formula proposed by Goland and Reissner [6], modifying the eccentricity factor so that it could be used for unbalanced adhesive joints. Therefore, in this case, two eccentric moments are generated, one at either end of the adherents $\left(k_{1}\right.$ and $\left.k_{2}\right)$. Oplinger [11] then modified the eccentricity factor formula to have a more approximate value. His estimation included the thickness $t_{b}$ and adhesive shear modulus $G_{b}$ using the parameter $R$. In contrast to the formula devised by Goland and Reissner [6], in Oplinger's formula [11] the greatest differences in the eccentricity factor $k$ are generated for thin adherent thicknesses. Zhao [28] proposed the estimation of the bending moment generated by the eccentricity, assuming that the adhesive only deforms at its ends. The proposed formula works for single balanced or unbalanced joints with an adhesive length between 25 and $50 \mathrm{~mm}$ and thin adherent thicknesses (steel $<4 \mathrm{~mm}$, aluminium $<6 \mathrm{~mm}$ ). The formulas proposed by Zhao [28] for the eccentric moment in the upper and lower adherent for unbalanced joints are:

$$
\begin{aligned}
M_{1} & =\frac{0.5 \cdot T \cdot\left(t_{1}+t_{2}\right) \cdot \zeta_{2}}{\zeta_{2}+\zeta_{1} \cdot \zeta_{2} \cdot l+\zeta_{1}} \\
M_{2} & =\frac{0.5 \cdot T \cdot\left(t_{1}+t_{2}\right) \cdot \zeta_{1}}{\zeta_{2}+\zeta_{1} \cdot \zeta_{2} \cdot l+\zeta_{1}}
\end{aligned}
$$

Where:

$$
\zeta_{i}=\sqrt{\frac{T}{D_{i}}}
$$

For balanced joints, Zhao's [28] proposed formula is:

$$
M=\frac{T \cdot t \cdot k}{2}
$$

Table 5 presents a summary of the eccentricity factors that are proposed in the stated methods.

Table 5 Eccentricity factors, $k$.

\begin{tabular}{ll}
\hline METHOD & ECCENTRICITY FACTORS \\
\hline $\begin{array}{l}\text { Goland and Reissner } \\
\text { Hart-Smith [8] }\end{array}$ & $k=\frac{1}{1+2 \cdot \sqrt{2} \cdot \tanh \left[\left(\frac{l}{2 \cdot t}\right) \cdot \sqrt{\left.\frac{3 \cdot p \cdot\left(1-v^{2}\right)}{2 \cdot E}\right]}\right]}$ \\
& $k_{i}=\frac{1}{1+\xi_{i} \cdot c+\frac{1}{6}\left(\xi_{i} \cdot c\right)^{2}}$ \\
Oplinger [11] & $k_{n}=\frac{R_{1} \cdot\left(1+R^{2} \cdot C_{2}\right)+8 \cdot R_{2} \cdot \frac{T_{h 21}}{T_{h 22}} \cdot R \cdot\left(C_{1}-C_{2}\right)}{R_{1}+8 \cdot R_{2} \cdot \frac{T_{h 21}}{T_{h 22}} \cdot R \cdot C_{1}+\sqrt{8} \cdot\left(1+R^{2} \cdot C_{1}\right) \cdot \frac{T_{h 21}}{T_{h 1}}}$ \\
\hline
\end{tabular}




\begin{tabular}{l} 
Zhao [28] $\quad k=\frac{1}{1+c \zeta}$ \\
\hline
\end{tabular}

\subsubsection{Adhesive stresses}

Tables 6 and 7 summarize the formulas for calculating the maximum shear and normal stresses at the ends of the adhesive, as indicated.

Renton and Vinson [13] graphically presented the distribution of the normal and shear stresses (transverse and longitudinal) of the adherent in a single-lap joint, the maximum stresses being expected at the ends of the adherents. Their work also showed that the variation of the stresses through the thickness of the adherent are higher and are generated in the upper or lower part of the ends of the adherents.

Table 6 Shear stress formulas.

\begin{tabular}{|c|c|}
\hline METHOD & MAXIMUM SHEAR STRESS \\
\hline Volkersen [5] & $\tau_{\max }=\frac{\lambda \cdot l}{2 \cdot \tanh (0.5 \cdot \lambda \cdot l)} \cdot \tau_{\text {avg }}$ \\
\hline $\begin{array}{l}\text { Goland and } \\
\text { Reissner [6] }\end{array}$ & $\tau_{\max }=\frac{p}{b \cdot l} \cdot\left[\left(\frac{1+3 \cdot k}{4}\right) \cdot \frac{\alpha \cdot l}{\tanh (\alpha \cdot l)}+\frac{3 \cdot\left(1-k^{\prime}\right)}{4}\right]$ \\
\hline $\begin{array}{l}\text { Hart-Smith } \\
{[8]^{(*)}}\end{array}$ & $\tau_{\text {max }}=\tau_{\text {avg }} \cdot\left\{1+\left[1+\frac{3 \cdot k_{1} \cdot\left(1-v_{1}^{2}\right)}{k_{b}}\left(1+\frac{n}{t_{1}}\right)\right] \cdot\left[\frac{\lambda^{2}}{4 \cdot \lambda^{\prime 2}}\right] \cdot\left[\frac{2 \cdot \lambda^{\prime} \cdot c}{\tanh \left(2 \cdot \lambda^{\prime} \cdot c\right)}-1\right]\right\}$ \\
\hline Allman [9] & $\tau_{0 \max }=\frac{3 \cdot T}{8 \cdot a}\left\{(1-k)+\frac{K \cdot e^{-\omega_{2} \cdot \bar{\xi}}}{\sqrt{\left(1+\left(\omega_{2} / \omega_{1}\right)^{2}\right.}}\right\}$ \\
\hline $\begin{array}{l}\text { Bigwood and } \\
\text { Crocombe [10] }\end{array}$ & $\begin{array}{l}\tau_{\max }=\tau_{V}+\tau_{M}+\tau_{T} \\
\tau_{V}=\frac{3 \cdot V}{4 \cdot h_{1}} \quad \tau_{M}=\frac{3 \cdot \alpha_{1} \cdot M}{h_{1} \cdot\left(\alpha_{1}+\alpha_{2}\right)^{0.5}} \\
\tau_{T}=\frac{-\alpha_{1} \cdot T}{2 \cdot\left(\alpha_{1}+\alpha_{2}\right)^{0.5}}\end{array}$ \\
\hline Oplinger [11] & $\tau_{\max }=\sigma_{x} \cdot\left[\frac{\sqrt{8}}{8} \cdot \beta \cdot\left(1+3 \cdot k_{n}\right) \cdot \frac{1}{T_{h 22}}+\frac{3}{8 \cdot \sqrt{8}} \cdot U \cdot\left(1-k_{n}\right) \cdot \frac{1}{T_{h 21}}\right]$ \\
\hline Zou [12] & $\tau_{\max }=\frac{G_{a} \cdot N \cdot\left(4 \cdot k_{11}+k \cdot k_{14} \cdot h^{2}\right)}{2 \cdot \zeta \cdot h_{a}}$ \\
\hline
\end{tabular}

\section{Formulas for ship applications}

The adhesive single-lap joint is mostly used in shipbuilding processes to lengthen the hull or superstructure or to reinforce FRP panels. Depending on the case, it is first necessary to 
estimate the forces or the eccentricity moment to be applied to each joint, then to estimate the minimum length of the adhesive and the interlaminate stresses. Table 8 shows the recommended values of the interlaminar design stresses of a reinforced laminate panel.

Considering a limiting stress fraction of 0.33 and based on the ultimate strength $S_{U}$, the FRP panel design stress $S_{D}$ is estimated:

$$
S_{D}=0.33 \cdot S_{U}
$$

A guide to limiting stress fraction is proposed in [29]. Clark [7] suggests using a safety factor between the interval $[1.5,10]$, depending on the laminate factors.

Table 7 Normal stress formulas.

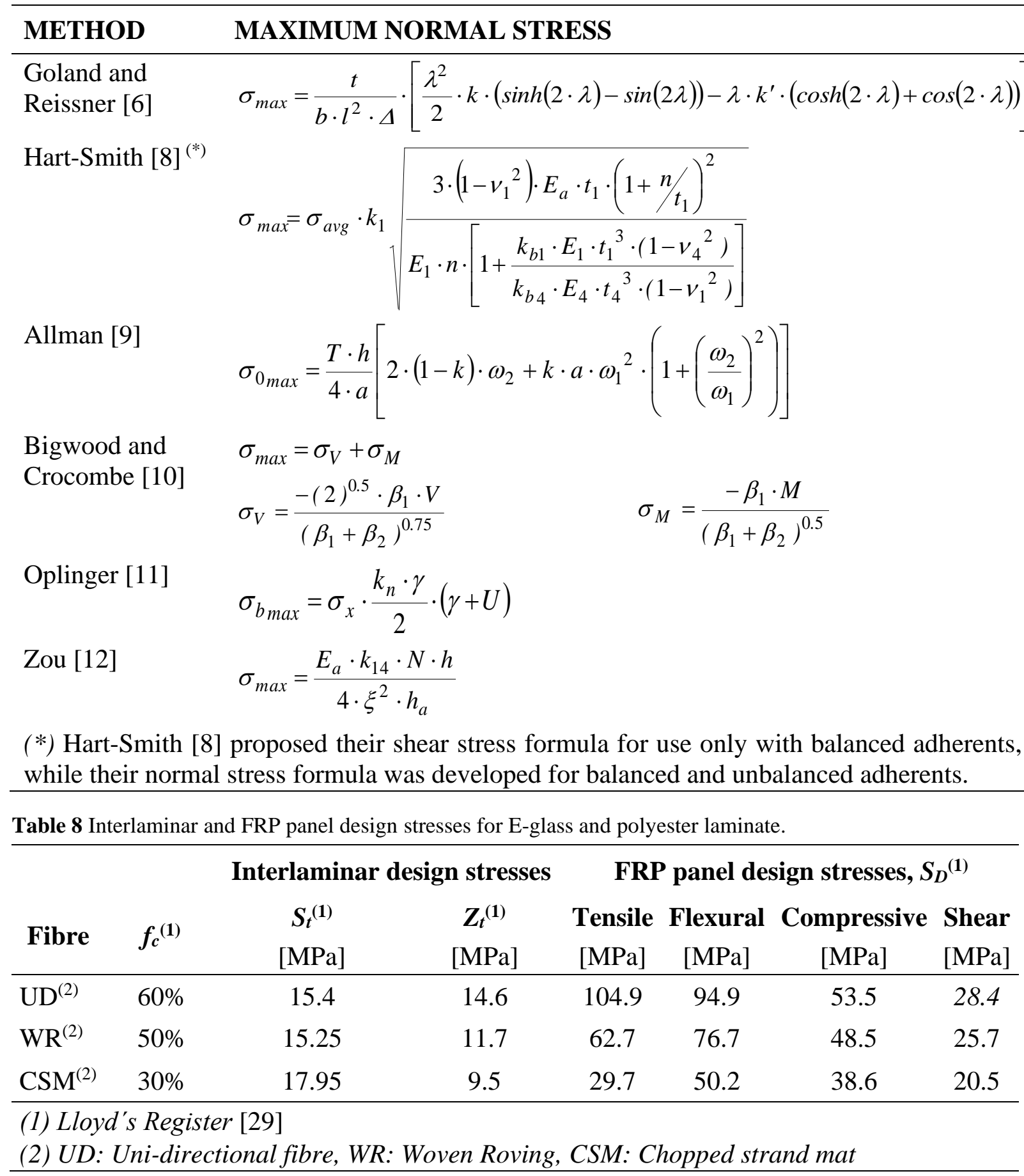


3.1. The joint length between stiffeners and composite panels

For adhesive joint applications with composite adherents when joining a stiffener or beam to panels, Lloyd's Register [29] recommends the following as the minimum staggered length for an adhesive joint:

$$
l=25+15 \cdot(n-1)
$$

And:

$$
l \geq 20 \cdot t_{f}
$$

Where $t_{f}$ is the thickness of the upper adherent and $n$ is the number of layers.

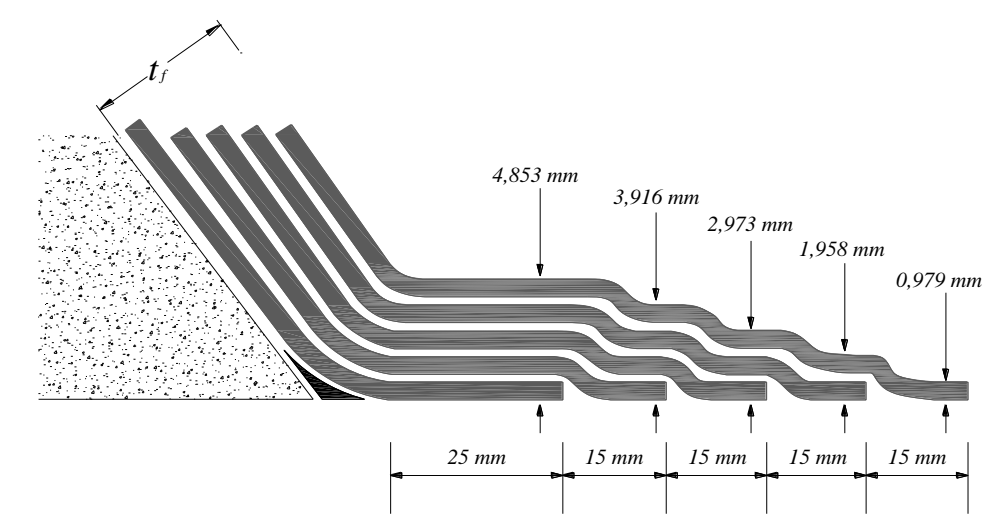

Fig. 8: Detail of the staggered adhesive joint length recommended by Lloyd's Register [29]. girder.

In any case, the number of layers of $t_{f}$ depends on the laminate of the stiffener or the

\subsection{Minimum joint length for lengthening}

The lengthening can be applied to a hull or a superstructure, see Fig. 9. In both cases, it is necessary to determine the forces applied in the joint. These forces can be estimated from the bending stresses and moment, as indicated in the following:

- Hull lengthening: The bending stress is calculated as a result of the hull girder stress analysis following naval architecture recommendations; it is first necessary to obtain the weight distribution curve to estimate the bending moment in calm water. Then, the wave bending moment is obtained following classification societies' formulas. The total bending moment $M_{f}$ is the sum of them. Once the lengthening section modulus has been defined, the bending stress $\underline{\sigma}_{a v g}$ is obtained using formula (8b). 

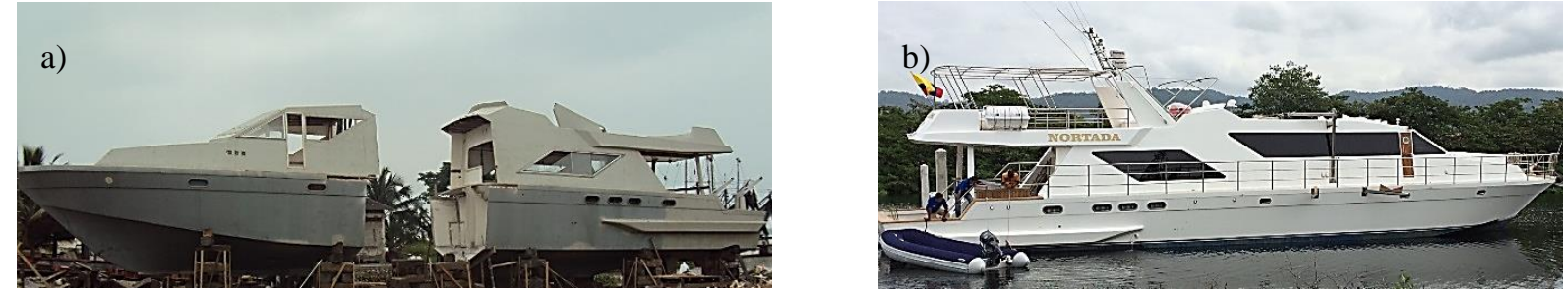

Fig. 9: Diving yacht: a) Lengthening, $+3.55 \mathrm{~m}$, in the midsection; b) final overall length $25.66 \mathrm{~m}$. Courtesy of Tecnavin S.A.

- Superstructure lengthening: The bending stress calculation is like that used for hull lengthening, with the difference being that the superstructure section modulus should be used.

Finally, the estimation of the minimum joint length for the lengthening $(l)$ is developed from the formula for a double-lap joint length [23] due to symmetry of the joint at lengthening:

$$
l=\left(\frac{\sigma_{a v g}}{\tau_{a}}+\frac{4}{\beta}\right) \cdot \bar{t}
$$

Where

$$
\begin{gathered}
\tau_{a}=\frac{\tau_{a-\text { yield }}}{10 \cdot f_{s}} \\
\sigma_{\text {avg }}=\frac{M_{f}}{S M}
\end{gathered}
$$

Where $\sigma_{a v g}$ is the bending stress; $S M$ is the section modulus, $\tau_{a}$ is the design shear stress of the adhesive, $\tau_{a-y i e l d}$ is the yield shear stress of the adhesive, $\bar{t}$ is the panel thickness and $f_{s}$ is the safety factor[29].

Once the length of the overlapping joint of the respective lengthening is estimated, it is advisable to use the quadratic criterion of failure of interlaminar forces to validate the design [1].

\subsection{Relationship to estimate the normal stress of a non-balanced joint}

Once the normal stress of the balanced joint is known (Table 7), the following relationship is proposed to estimate the normal stress for a non-balanced joint.

$$
\frac{\sigma_{\max (N B)}}{\sigma_{\max (B)}}=\left[\frac{2}{1+\frac{k_{b 1} \cdot E_{1} \cdot\left(1-v_{2}\right)^{2} \cdot t_{1}{ }^{3}}{k_{b 2} \cdot E_{2} \cdot\left(1-v_{1}\right)^{2} \cdot t_{2}{ }^{3}}}\right]^{1 / 2}
$$

Where adherent 1 corresponds to the reinforcement laminate and adherent 2 is the FRP panel. 


\subsection{Application of single lap joint}

\subsubsection{Single lap joint applied to hybrid tubular joint}

An application of the adhesive joint is presented in Dominguez [1] to develop a methodology for a hybrid bond with FRP laminated tubular reinforcement that allows the bonding between FRP panels and steel decks.

\subsubsection{Yacht hull lengthening}

The study of the joint for the elongation of a diving yacht built with hand layup using polyester resin and type E fibreglass is presented below, as shown in Fig. 9. In this application, the adhesive joints will be considered as balanced on the hull bottom, hull side, and deck. The yacht main data is shown in table 9 and laminates properties in table 10.

Table 9 Diving Yacht Main Data

\begin{tabular}{lccc}
\hline \multicolumn{1}{c}{ Variable } & Symbol & Value & Unit \\
\hline Length & $L$ & 25.66 & $\mathrm{~m}$ \\
Breadth & $B$ & 5.40 & $\mathrm{~m}$ \\
Depth & $D$ & 2.82 & $\mathrm{~m}$ \\
Draft & $H$ & 1.15 & $\mathrm{~m}$ \\
Displacement & $\Delta$ & 60.60 & ton \\
Block coefficient & $C b$ & 0.475 & \\
Speed & $v$ & 12 & knots \\
${ }^{(* *)}$ Minimum Cb value for vertical wave bending \\
moment calculation 0.6,[29]. \\
\hline
\end{tabular}

Middle Section

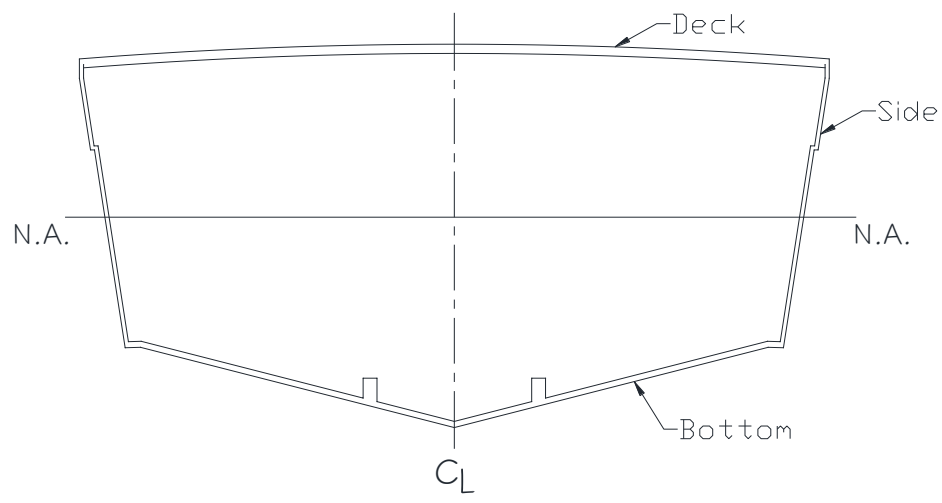

Fig. 10: Diving yacht middle section.

Lloyds Register [29] suggest $13.8 \mathrm{~N} / \mathrm{mm}^{2}$ as yield shear strength $\tau_{a-y i e l d}$ and a safety factor $f_{s}$ of 3 .

From Fig A.9, the maximum still water bending moment $M_{S}$ is $1002 \mathrm{kN}-\mathrm{m}$. The maximum vertical wave bending moment $M_{W}$ of $2571 \mathrm{kN}-\mathrm{m}$, is calculated using formulas of Lloyd's Register [29], getting a total bending moment of $M_{f}$ de $3573 \mathrm{kN}-\mathrm{m}$. 
On Fig. 10 and Table 11 the amidships section of the diving yacht is shown, where a section modulus $S M$ of $0.502 \mathrm{~m}^{3}$ for the hull bottom and $0.611 \mathrm{~m}^{3}$ for the deck are calculated, the smallest modulus will be used in the calculations.

Table 10 Equivalent isotropic properties and thickness of Diving Yacht

\begin{tabular}{lcc}
\hline \multicolumn{1}{c}{ Variable } & Value & Unit \\
\hline Side thickness & 0.030 & $\mathrm{~m}$ \\
Bottom thickness & 0.044 & $\mathrm{~m}$ \\
Deck thickness & 0.044 & $\mathrm{~m}$ \\
Resin thickness (adhesive) $_{\text {Equivalent elastic modulus of side }{ }^{(* *)}}$ & 0.0025 & $\mathrm{~m}$ \\
Equivalent elastic modulus of bottom $^{(* *)}$ & 2756 & $\mathrm{MPa}$ \\
Equivalent elastic modulus of deck $^{(* *)}$ & 2338 & $\mathrm{MPa}$ \\
Elastic modulus of the resin $_{\text {Shear modulus of the resin }}$ & 3438 & $\mathrm{MPa}$ \\
(**) For the calculation of equivalent modules, the formulas indicated $^{\text {in Dominguez [1]- Appendix B.1.3 have been used. }}$ \\
\hline
\end{tabular}

The maximum value between the results of Table 12 and Table 13 is selected, $0.696 \mathrm{~m}$.

The adhesive joint for superstructure lengthening must be estimated with the same procedure used for the hull.

Table 11 Estimation of section modulus and bending stress

\begin{tabular}{lccc}
\hline \multicolumn{1}{c}{ Variable } & Symbol & Value & Unit \\
\hline Area & $A$ & 0.614 & $\mathrm{~m}^{2}$ \\
Distance from bottom to the neutral axis & $N A_{\text {bottom }}$ & 1.551 & $\mathrm{~m}$ \\
Distance from deck to the neutral axis & $N A_{\text {deck }}$ & 1.275 & $\mathrm{~m}$ \\
Inertia in the neutral axis & $I_{N A}$ & 0.778 & $\mathrm{~m}^{4}$ \\
Section modulus (bottom) & $S M_{\text {bottom }}$ & 0.502 & $\mathrm{~m}^{3}$ \\
Section modulus (deck) & $S M_{\text {deck }}$ & 0.611 & $\mathrm{~m}^{3}$ \\
Total bending moment & $M_{f}$ & 3573 & $\mathrm{kN}-\mathrm{m}$ \\
Bending stress (bottom) & $\sigma_{\text {bottom }}$ & 6.626 & $\mathrm{~N} / \mathrm{mm}^{2}$ \\
Bending stress (deck) & $\sigma_{\text {deck }}$ & 5.446 & $\mathrm{~N} / \mathrm{mm}^{2}$ \\
\hline
\end{tabular}

On Table 12 the estimation of the minimum joint length for hull lengthening is presented using the equation (7): 
Table 12 Estimation of minimum joint length

\begin{tabular}{lccc}
\hline \multicolumn{1}{c}{ Variable } & Symbol & Value & Unit \\
\hline Section modulus (bottom) & $S M$ & 0.502 & $\mathrm{~m}^{3}$ \\
Total bending moment & $M_{f}$ & 3573 & $\mathrm{kN}-\mathrm{m}$ \\
Yield shear stress & $\tau_{a-\text {-yield }}$ & 13800 & $\mathrm{kN} / \mathrm{m}^{2}$ \\
Safety factor & $f_{s}$ & 3.00 & - \\
Average thickness & $\bar{t}$ & 0.044 & $\mathrm{~m}$ \\
Parameter & $\beta$ & 11.33 & - \\
Bending stress - equation (8b) & $\sigma_{a v g}$ & 7118 & $\mathrm{kN} / \mathrm{m}^{2}$ \\
Design shear stress - equation (8a) & $\tau_{a}$ & 460 & $\mathrm{kN} / \mathrm{m}^{2}$ \\
Minimum joint length - equation (7) & $\boldsymbol{l}$ & $\mathbf{0 . 6 9 6}$ & $\mathbf{m}$ \\
\hline
\end{tabular}

On Table 13 the estimation of the minimum joint length for hull lengthening is presented using the formulas of Clark [7] shown in Table 4 :

Table 13 Estimation of minimum joint length, Clark [7]

\begin{tabular}{lccc}
\hline \multicolumn{1}{c}{ Variable } & Symbol & Value & Unit \\
\hline Assumed stress fraction & $\tau_{\text {a-yield }}$ & 21.399 & - \\
& $\tau_{\text {avg }}$ & & \\
Average thickness & $\bar{t}$ & 0.044 & $\mathrm{~m}$ \\
Parameter & $\beta$ & 11.33 & - \\
Minimum joint length - Clark [7] & $\boldsymbol{l}$ & $\mathbf{0 . 1 9 6}$ & $\mathbf{m}$ \\
\hline
\end{tabular}

\section{Features influencing the single-lap joint on marine applications}

The various studies covered in this review propose formulas that show good applicability for use in the industry. However, in designing an adhesive single-lap joint for marine applications, the following aspects should be considered: eccentricity moment, adherent thickness, adhesive length, adherent properties, and adhesive strength.

\subsection{Eccentric moment}

Hart-Smith presented a formula for the eccentricity factor $k$ that is easy to apply and useful for different thicknesses of adherents. Oplinger proposed a formula for eccentricity factor $k$ that is more accurate compared to FEA calculations; however, it is limited in that it only applies to adherents of the same thickness. Goland and Reissner were the first to introduce the formula for the eccentricity factor $k$; however, this can only be applied in the context of balanced joints and thin adherent thicknesses. Bigwood and Crocombe and Zou did not directly consider the eccentricity factor $k$ in their calculations.

\subsection{Adherent thickness}

In marine applications, the variability of the adherent thicknesses is important. To address this variability, the methods proposed by Hart-Smith, Bigwood and Crocombe, and Zou consider the formulas to calculate the shear and normal stresses in the adhesive. The other methodologies were proposed for balanced joints. 


\subsection{Adhesive length}

In marine applications, only the formulations for the elastic behaviour of the adhesive are considered; therefore, the strengths and the direction applied in the lap joint must be identified. In this context, three applications are identified, namely the reinforcement laminate on an FRP panel, the joint between two panels in a hull lengthening, and the joint in a superstructure lengthening.

Regarding the bonding in the reinforcement of an FRP panel, Renton and Vinson made some recommendations for the relationship between joint length and the thickness of the adhesive; however, Lloyd's Register proposes a greater adhesive length in this case. Both authors recommended the bevelling of the adherent ends to decrease the respective stresses. Oplinger provided a formula that allows the calculation of the effective length; its adhesive length values are approximated to the Lloyd's Register formula when the adherent thickness is increased.

Regarding the joint between two panels of a hull lengthening, the formula proposed in section 3.2. is useful to evaluate the adhesive length with equal or unequal adherents' thickness. Alternatively, in cases of equal adherent thickness, the formula proposed by Clark can be used. When these two alternative formulas are used, the required adhesive joint length is to be the greater of the calculated values.

A superstructure lengthening is a case of hull lengthening. The particularity is that the adherents are more likely to be of different thicknesses because it is possible to present the joint between two sandwich panels as well as a combination of a sandwich panel and a single laminate.

From the joint lengths calculated in the application case of diving hull lengthening, it is shown the importance of considering the bending stresses of the hull girder, which is not considered by Clark [7].

A limitation when trying to lengthen a steel hull using FRP adhesive joints, in the middle section, is the difference between the modulus of elasticity of the two materials since it generates different elongations in the hull girder that will cause structural fractures by corrosion. The lengthening with FRP panels can be applied at one end of the hull, provided that the hybrid joint methodology is used taking into account the difference in the mentioned elongations.

\subsection{Adherent properties}

When joining a reinforcement FRP with an FRP panel, it is important to keep in mind the difference between the equivalent mechanical properties of the adherents because the adhesive stresses obtained with different adherent thicknesses are less efficient than those expected to be obtained with adherents of equal thickness.

\subsection{Adhesive stress}

The formulas developed by Hart-Smith, Bigwood and Crocombe and Zou yield very similar values for normal stresses. Zou's proposed formulas can calculate the stresses in the adhesive only for equal adherent thicknesses. Hart-Smith's formula allows the normal stresses to be calculated for different adherent thicknesses, whereas shear stresses can be calculated only for balanced joints. Bigwood and Crocombe formula has the advantage that it allows the normal and shear stresses to be calculated for different adherent thicknesses. In all revised formulas, the maximum stresses are shown at the ends of the adhesive joint. 


\section{Concluding remarks}

In the previous sections, the researchers considered the adhesive for a single-lap joint as an isotropic material. Furthermore, thirty per cent of the proposed methodologies considered adherents as orthotropic or anisotropic in their analysis. Due to the mathematical complexity involved, some authors who used anisotropic materials recommended performing a numerical analysis or FEA to complete the solution.

The authors who involved nonlinearity in their analysis concluded that their results are more approximate compared to the results obtained in experimental tests.

The work of Hart-Smith contributed significantly to the utility of such formulas for single-lap joints since this author considered the importance of accounting for the plastic area of the adhesive. This is necessary because single-lap joints are subjected to large deformations, so the shear stresses generated could exceed the elastic limit, in which case a formula would estimate erroneous results.

Another practical conclusion, showed by Hart-Smith and Oterkus, is that an adhesive joint bevel of staggered type has shown to diminish the normal stress on ends. This bevel is recommended by Lloyd's Register to bond stiffeners to an FRP panel and to hull or superstructure lengthening.

The proposed equations (7) and (9), to estimate the minimum joint length and the stresses in the adhesive, respectively, are recommended to preliminary design. The resultant adhesive stresses are useful to estimate the interlaminar stresses of the first adjacent laminate layer; however, to complete FRP panel design, the interlaminar stresses of all laminate layers should be analysed. The last stage is beyond the scope of this study.

To avoid high interlaminar stresses at the ends of the adhesive joint in a lengthening study, it is necessary to make a stepped bevel of $l / t \approx 100$ for each layer. The adhesive joint has been considered to have the same thickness as the hull or superstructure, however, to avoid osmosis effects in the adhesive joint, it is necessary to seal on the opposite side with at least 3 layers using isophthalic NPG resin.

FUNDING: This research received no external funding

ACKNOWLEDGEMENTS: The authors thank the ESPOL Polytechnic University, Escuela Superior Politécnica del Litoral, Faculty of Maritime Engineering and Marine Sciences (FIMCM), for the facilities provided with the laboratory.

CONFLICTS OF INTEREST: The authors declare that they have no known competing for financial interests or personal relationships that could have appeared to have influenced the work reported in this paper. 
NOMENCLATURE

\begin{tabular}{|c|c|c|c|c|c|c|c|c|}
\hline Variables & 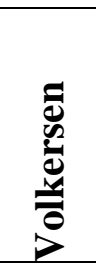 & 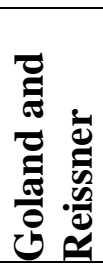 & : & 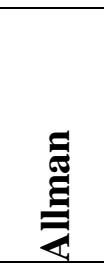 & 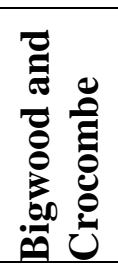 & 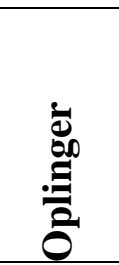 & $\stackrel{\overrightarrow{0}}{\mathrm{~N}}$ & $\stackrel{\text { T⿱乛龰 }}{\mathbf{N}}$ \\
\hline Overlap joint width & $\mathrm{b}$ & $\mathrm{b}$ & & & & & & \\
\hline Overlap joint length & 1 & 1 & 1 & & & 1 & & 1 \\
\hline Non-overlap joint length & & & & & & $1_{0}$ & & \\
\hline Elastic length of adhesive & & & d & & & & & \\
\hline $\begin{array}{l}\text { Average length of overlap } \\
\text { joint }\end{array}$ & c & & c & a & & & 1 & \\
\hline Adhesive thickness & $\mathrm{t}_{\mathrm{a}}$ & $\mathrm{t}_{\mathrm{a}}$ & $\mathrm{n}$ & $\mathrm{t}$ & $\mathrm{t}$ & $t_{b}$ & $\mathrm{~h}_{\mathrm{a}}$ & $\mathrm{t}$ \\
\hline Adherents thickness & $\mathrm{t}_{1}, \mathrm{t}_{2}$ & $\mathrm{t}$ & $\begin{array}{c}\mathrm{t}, \mathrm{t}_{1} \\
\mathrm{t}_{4}\end{array}$ & $\begin{array}{c}\mathrm{h}, \mathrm{h}_{1}, \\
\mathrm{~h}_{2}\end{array}$ & $\mathrm{~h}_{1}, \mathrm{~h}_{2}$ & $\mathrm{t}, \mathrm{t}_{\mathrm{u}}, \mathrm{t}_{\mathrm{l}}$ & $\begin{array}{c}\mathrm{h}, \mathrm{h}_{1}, \\
\mathrm{~h}_{2}\end{array}$ & $\mathrm{t}_{1}, \mathrm{t}_{2}$ \\
\hline $\begin{array}{l}\text { Elastic modulus of the } \\
\text { adhesive }\end{array}$ & & $\mathrm{E}_{\mathrm{a}}$ & $\mathrm{E}_{\mathrm{a}}$ & & $\mathrm{E}_{\mathrm{a}}$ & $\mathrm{E}_{\mathrm{b}}$ & $\mathrm{E}_{\mathrm{a}}$ & \\
\hline $\begin{array}{l}\text { Elastic modulus of } \\
\text { adherents }\end{array}$ & $\begin{array}{l}E_{1} \\
E_{2}\end{array}$ & $\mathrm{E}$ & $\begin{array}{l}E_{1}, \\
E_{4}\end{array}$ & $\mathrm{E}$ & $\begin{array}{l}E_{1}, \\
E_{2}\end{array}$ & $\begin{array}{c}\mathrm{E}, \mathrm{E}_{\mathrm{u}} \\
\mathrm{E}_{\mathrm{l}}\end{array}$ & $\begin{array}{l}E_{1}, \\
E_{2}\end{array}$ & \\
\hline $\begin{array}{l}\text { Shear modulus of the } \\
\text { adhesive }\end{array}$ & $\mathrm{G}_{\mathrm{a}}$ & $\mathrm{G}_{\mathrm{a}}$ & $\mathrm{G}_{\mathrm{a}}$ & & $\mathrm{G}_{\mathrm{a}}$ & $\mathrm{G}_{\mathrm{b}}$ & $\mathrm{G}_{\mathrm{a}}$ & \\
\hline $\begin{array}{l}\text { Poisson number of } \\
\text { adhesives }\end{array}$ & & $v_{a}$ & $v_{\mathrm{a}}$ & & $v_{\mathrm{a}}$ & $v_{b}$ & $v_{\mathrm{a}}$ & \\
\hline $\begin{array}{l}\text { Poisson number of } \\
\text { adherents }\end{array}$ & & $v$ & $\begin{array}{c}v, v_{1} \\
v_{4}\end{array}$ & $v$ & $v_{1}, v_{2}$ & $\begin{array}{c}v, v_{\mathrm{u}} \\
v_{\mathrm{l}}\end{array}$ & $v_{1}, v_{2}$ & \\
\hline $\begin{array}{l}\text { Flexural stiffness of the } \\
\text { adhesive }\end{array}$ & & & $\mathrm{D}_{\mathrm{a}}$ & & & & $\begin{array}{c}\mathrm{D}_{\text {overl }} \\
\text { ap }\end{array}$ & \\
\hline $\begin{array}{l}\text { Flexural stiffness of } \\
\text { adherents }\end{array}$ & & & $\begin{array}{l}\mathrm{D}_{1} \\
\mathrm{D}_{4}\end{array}$ & & $\begin{array}{l}\mathrm{D}_{1} \\
\mathrm{D}_{2}\end{array}$ & $\begin{array}{c}\mathrm{D}_{\mathrm{u}} \\
\mathrm{D}_{\mathrm{l}}\end{array}$ & $\mathrm{D}_{11}$ & $\mathrm{D}_{\mathrm{i}}$ \\
\hline Axial load & $\mathrm{P}$ & $\mathrm{P}, \mathrm{p}$ & $\mathrm{P}$ & $\mathrm{T}$ & & $\mathrm{T}$ & $\mathrm{N}$ & $\mathrm{T}$ \\
\hline $\begin{array}{l}\text { Average shear stress } \\
\text { Average normal stress }\end{array}$ & $\tau_{\text {avg }}$ & & $\begin{array}{l}\tau_{\text {avg }} \\
\sigma_{\text {avg }}\end{array}$ & & & $\sigma_{\mathrm{x}}$ & & \\
\hline
\end{tabular}

\section{REFERENCES}

[1] Dominguez F., Carral L., The Hybrid Joints between an FRP Panel and a Steel Panel through Tubular Reinforcements: A Methodology for Interlaminar Stress Calculations, Appl. Sci., 2020, 10, 3962. https://doi.org/10.3390/app10113962

[2] Dominguez J., Carral L., Hybrid Joint Between Steel Deck and Fiberglass Superstructure, Proceedings of the Multidisciplinary International Conference of Research Applied to Defense and Security MICRADS; Howlett, R.J., Bournemouth University and KES International, Eds.; Springer, Switzerland, 2018, 94, 284295. https://doi.org/10.1007/978-3-319-78605-6_24

[3] Dominguez J., Carral L., Superstructure Design: Combination of Fiberglass Panel and Tubular Structure with Naval Steel Hull, Proceedings of the 25th Pan-American Conference of Naval EngineeringCOPINAVAL 2017; Sáenz, A.V., Pereira, N.N., Couce, L.M.V., Formoso, J.A.F., Eds.; Springer, Switzerland, 2018, 81-91. https://doi.org/10.1007/978-3-319-89812-4_8

[4] Calì M., Pascoletti G., Gaeta M., Milazzo G., Ambu R., A New Generation of Bio-Composite Thermoplastic Filaments for a More Sustainable Design of Parts Manufactured by FDM, Appl. Sci. 2020, 10, 5852. https://doi.org/10.3390/app10175852

[5] Volkersen O., Die nietkraftverteilung in zugbeanspruchten nietverbindungen mit konstanten laschenquerschnitten, Luftfahrtforschung, 1938, 7, 15-47.

[6] Goland M., Reissner E., The stresses in cemented joints, J Appl Mech, 1944, 11, A17-A27.

[7] Clark J. L., Structural Design of Polymer Composites - Eurocomp Design Code and Handbook, Halcrow Polymerics Ltd, CRC Press, London, 1996. https://doi.org/10.1201/9781482294811 
[8] Hart-Smith L., Adhesive bonded single-lap joints, Technical Report; National Aeronautics and Space Administration: California 90846, January 1973.

[9] Allman D., A theory for elastic stresses in adhesive-bonded lap joints, Quarterly Journal of Mechanics and Applied Mathematics, London, 1977, 30, 415-436. https://doi.org/10.1093/qjmam/30.4.415

[10] Bigwood D., Crocombe A., Elastic analysis and engineering design formulae for bonded joints, Adhesion and Adhesives, University of Surrey, UK, October 1989, 9. https://doi.org/10.1016/0143-7496(89)90066-3

[11] Oplinger D., A layered beam theory for single-lap joints, U.S. Army Materials Technology Laboratory, Watertown Massachusetts 02172-000 1, June 1991, 44 pp.

[12] Zou G., Shahin K., Taheri F., An analytical solution for the analysis of symmetric composite adhesively bonded joints, Composite Structures, $2004, \quad 65: 3-4, \quad 499-510$. https://doi.org/10.1016/j.compstruct.2004.01.007

[13] Renton W., Vinson J., The Analysis and design of composite material bonded joints under static and fatigue loadings, Department of Mechanical and Aerospace Engineering, University of Delaware, Air Force Office of Scientific Research, August 1973. Available online: https://apps.dtic.mil/dtic/tr/fulltext/u2/766932.pdf (accessed on 20 April 2020)

[14] Ojalvo I., Eidinoff H., Bond Thickness Effects Upon Stresses in Single-lap Adhesive Joints, AIAA Journal, Society of Automotive Engineers, Congress and Exposition Cobo Hall, March 1978, 16:3, 204 - 211. https://doi.org/10.2514/3.60878

[15] Delale F., Erdogan F., Aydinogly M., Stresses in Adhesively bonded joints: a closed-form solution, Journal of Composite Material, Saej Journal, NASA, Contractor Report 165638, May 1981, 15:3, 249-271. https://doi.org/10.1177/002199838101500305

[16] Adams R., Mallick V., A method for the stress analysis of lap joints, Taylor \& Francis, The Journal of Adhesive, London, March 1992, 38:3-4, 199-217. https://doi.org/10.1080/00218469208030455

[17] Tong L., Bond Strength for adhesive-bonded single-lap joints, Acta Mechanical, Springer - Verlag, March 1996, 117, 101-113. https://doi.org/10.1007/BF01181040

[18] Smeltzer S., Klang E., Analysis method for inelastic, adhesively bonded joints with anisotropic adherends, NASA Technical Reports Server, Proceedings of the American Society for Composites 18th Technical Conference, Paper Number 104, January 2003. Available online: https://ntrs.nasa.gov/search.jsp?R=20040034208 (accessed on 20 April 2020)

[19] Calik A., Effect of adherend shape on stress concentration reduction of adhesively bonded single-lap joint, Engineering Review, January 2016, 36:1, 29-34. Available online: https://hrcak.srce.hr/151838 (accessed on 20 April 2020)

[20] Oterkus E., Barut A., Madenci E., Smeltzer S., Ambur D., Nonlinear analysis of bonded composite singlelap joints, American Institute of Aeronautics and Astronautics, Collection of Technical Papers, 45th AIAA/ASME/ASCE/AHS/ASC Structures, Structural Dynamics and Materials Conference, Palm Springs, California, April 2004, 1, 555-572. https://doi.org/10.2514/6.2004-1560

[21] Hollaway L., Handbook of polymer composites for engineers, Woodhead Publishing Ltd, British Plastic Federation, Cambridge, England, 1994, ISBN 1855731290.

[22] Banea M., Da Silva L., Adhesively bonded joints in composite materials: an overview, Journal of Materials: Design and Applications, Proceedings of the Institution of Mechanical Engineers, January 2009, 23:1, 1-18. https://doi.org/10.1243/14644207JMDA219

[23] Hart-Smith L., Adhesive bonded double lap joints, Technical Report, National Aeronautics and Space Administration: California 90846, January 1973.

[24] Hart-Smith L., Non-classical adhesive bonded joints in practical aerospace construction, Technical Report, National Aeronautics and Space Administration: California 90846, January 1973.

[25] Hart-Smith L., Further developments in the design and analysis of adhesive-bonded structural joints, Joining of Composite Materials, ed. K. Kedward (West Conshohocken, PA: ASTM International), 1981, 3-31. https://doi.org/10.1520/STP33472S

[26] Hart-Smith L., Design methodology for bonded-bolted composite joints, Vol I: Analysis derivations and illustrative solutions, Technical Report AFWAL TR-81-3154, Ohio 45433, February 1982.

[27] Oplinger D., Stress analysis of composite joints, Advances in joining technology, Army Materials and Mechanics Research Center Watertown, Massachusetts, 1975, 405-452.

[28] Zhao X., Adams R., Da Silva L., A new method for the determination of bending moments in single-lap joints, International Journal of Adhesion \& Adhesives, September 2010, 30:2, 63-71. https://doi.org/10.1016/j.ijadhadh.2009.09.001

[29] Lloyds Register, Hull Construction in Composite, Rules and Regulations for the Classification of Special Service Craft, UK, July 2019.

[30] Bigwood D., Crocombe A., Non-linear adhesive-bonded joint design analyses, International Journal of Adhesion and Adhesives, UK, January 1990, 10:1, 31-41. https://doi.org/10.1016/0143-7496(90)90025-S 


\section{Appendix: Formulas for the shear and normal stresses of the adhesive}

A.1 Explicit methods:

A.1.1 Volkersen method (1938)
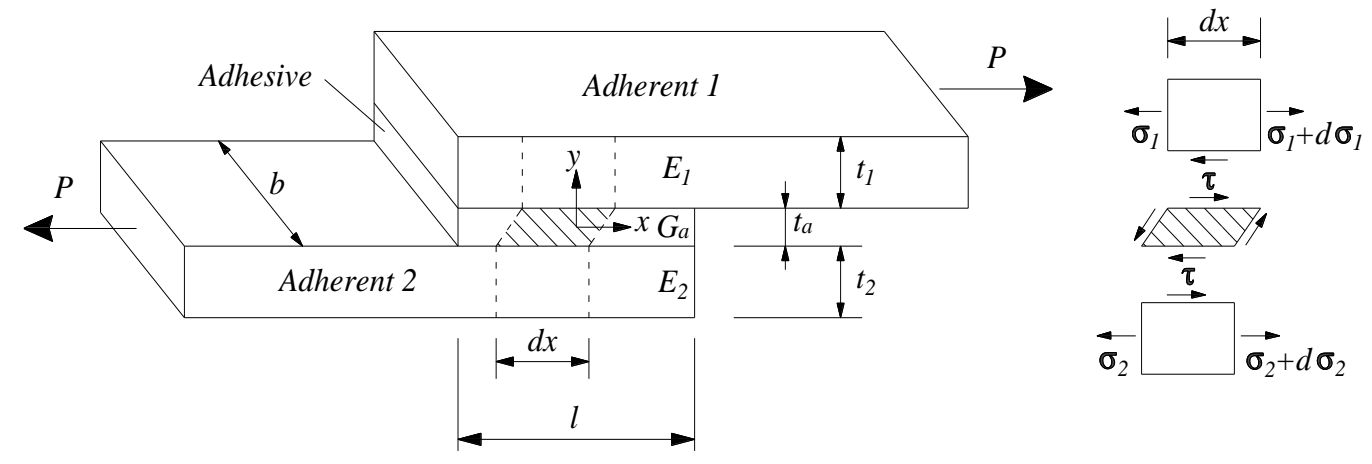

Fig. A 1 Single joint geometry; Volkersen [5].

The formulas for shear stress distribution; see Volkersen [5].

A.1.2 Goland and Reissner method (1944)

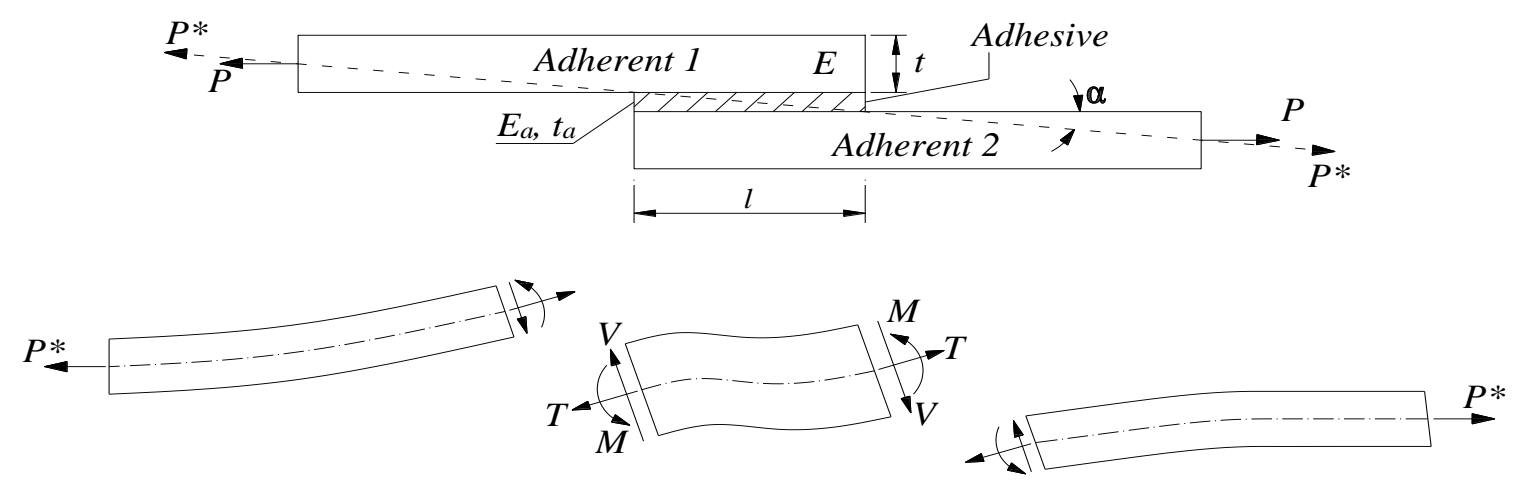

Fig. A 2 Single-lap joint geometry; Goland and Reissner [6].

The formulas to estimate the shear and normal stresses; see Goland and Reissner [6].

\section{A.1.3 Hart-Smith method (1973)}

Fig A.3 presents the geometry analysed by Hart-Smith [8] for a single balanced or unbalanced adhesive joint and the estimated shear and normal stress distributions for the adhesive.

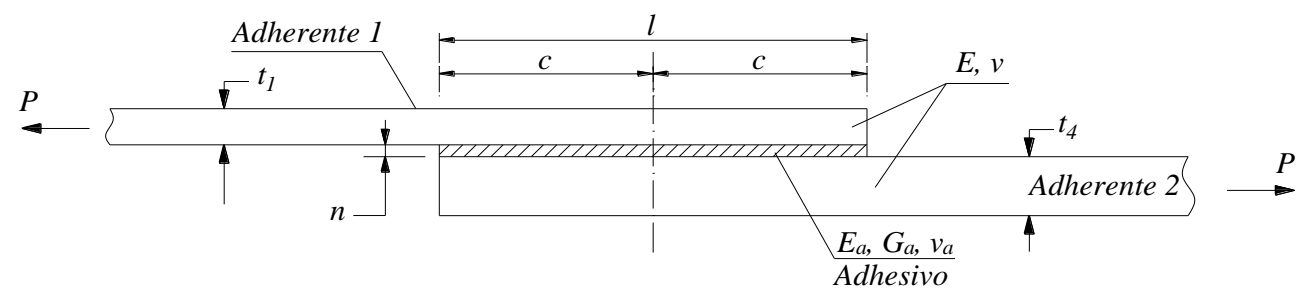

Fig. A 3 Single adhesive joint geometry; Hart-Smith [8]. 
The moment for a balanced joint generated by the eccentricity of the applied loads is:

$$
M_{0}=k_{1} \cdot P \cdot \frac{t_{1}}{2} \cdot\left(1+\frac{n}{t_{1}}\right)
$$

Being the formula for estimation of $k_{l}$ indicated in Table 5.

The parameters $\lambda$ and $\lambda^{\prime}$ for the calculation of the balanced joint shear stress, indicated in Table 6, are as follows:

$$
\lambda^{2}=\frac{2 \cdot G_{a}}{E_{1} \cdot t_{1} \cdot n} \quad \lambda^{\prime 2}=\left[\frac{1+3\left(1-v_{1}^{2}\right) / k_{b}}{4}\right] \cdot \lambda^{2}
$$

The parameter $\xi i$ is used for both balanced and unbalanced adherents:

$$
\xi_{i}^{2}=\frac{P}{D_{i}}=\frac{12 \cdot P \cdot\left(1-v_{i}^{2}\right)}{k_{b} \cdot E_{i} \cdot t_{i}{ }^{3}}
$$

The average shear and normal stresses are estimated as follows:

$$
\tau_{\text {avg }}=\frac{P}{l} \quad \sigma_{\text {avg }}=\frac{P}{t}
$$

Where $t$ is the weakest adherent thickness, $P$ is the load per unit length, and $k_{b}$ is the stiffness coefficient of the material, which is 1 for isotropic materials.

A.1.4 Allman method (1977)

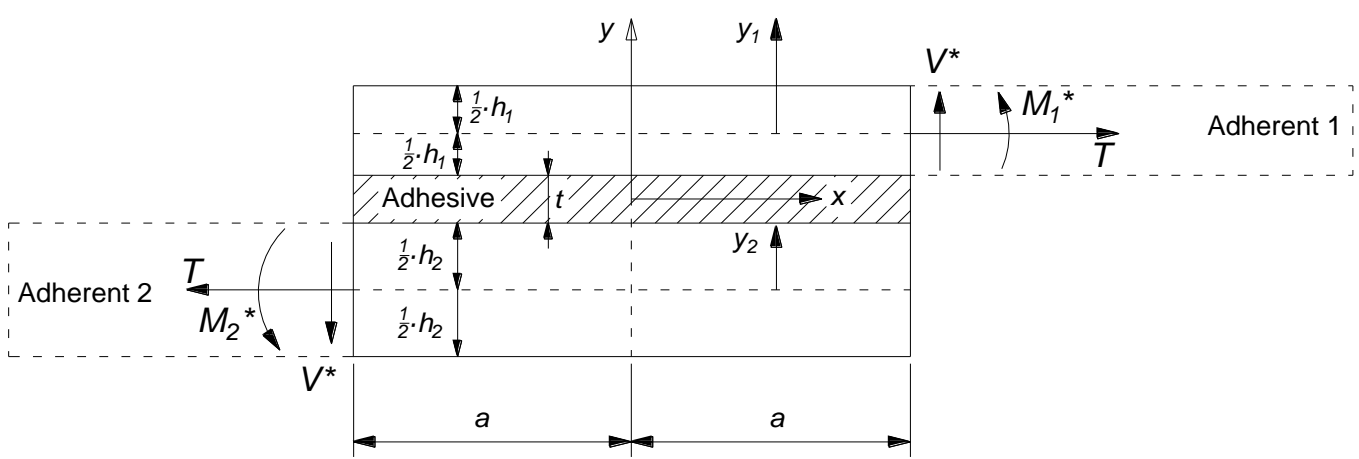




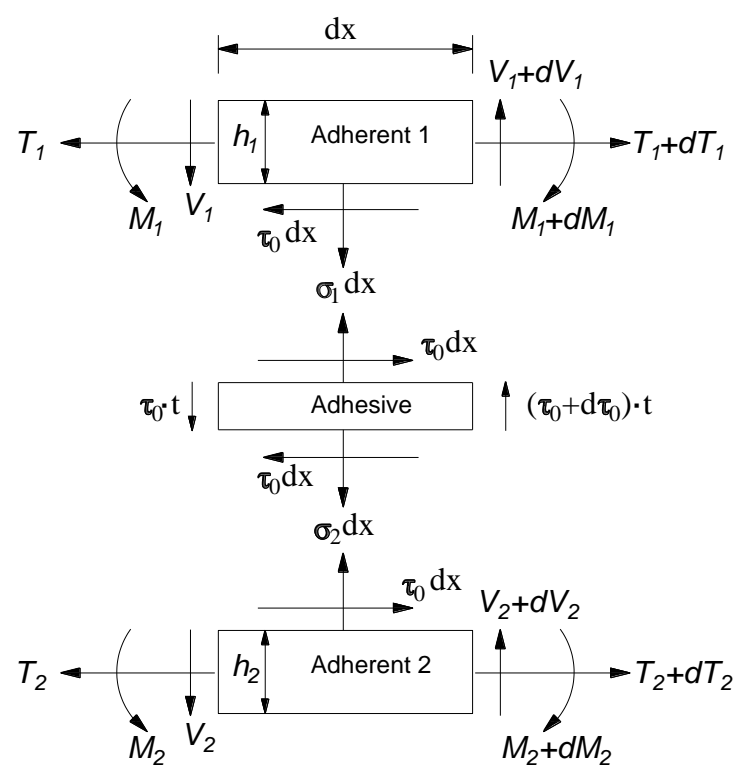

Fig. A 4 Single joint geometry; Allman [9].

The formulas to estimate the shear and normal stress; see Allman [9]

A.1.5 Bigwood and Crocombe method (1989)
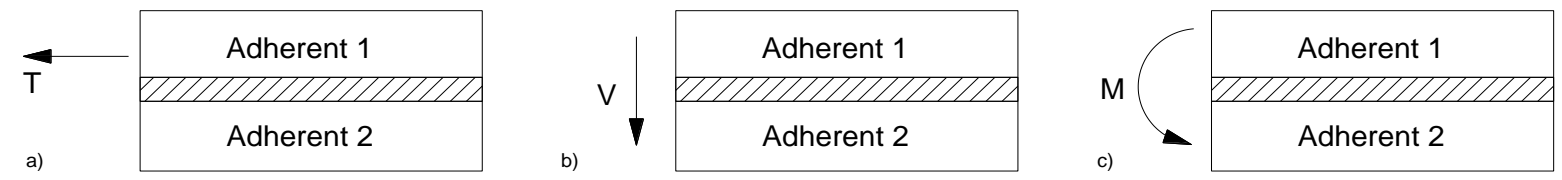

Fig. A 5 Scheme of loads applied to evaluate the stresses in the adhesive; a) application of tensile stress, b) application of shear stress, c) application of momentum [10].

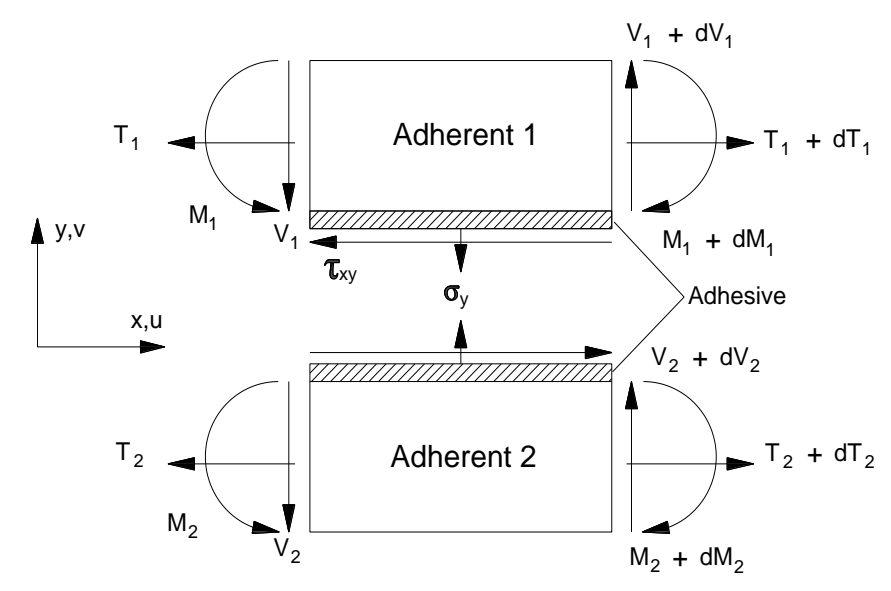

Fig. A6 Diagram of single joining forces; Bigwood [10].

Bigwood [10] simplified the equations of movements based on the consideration that the variations of the shear and normal stresses along the joint are small; the differential equations are:

$$
\frac{d^{4} \sigma_{y}}{\partial x^{4}}+4 K_{5}{ }^{4} \sigma_{y}=0
$$




$$
\frac{d^{3} \tau_{x y}}{\partial x^{3}}-K_{6^{2}} \frac{d \tau_{x y}}{\partial x}=0
$$

Where:

$$
\begin{aligned}
& K_{5}^{4}=\frac{E_{a}}{4 \cdot t}\left(\frac{1}{D_{1}}+\frac{1}{D_{2}}\right) \\
& K_{6}{ }^{2}=\frac{4 \cdot G_{a}}{t}\left(\frac{\left(1-v_{1}^{2}\right)}{E_{1} \cdot h_{1}}+\frac{\left(1-v_{2}^{2}\right)}{E_{2} \cdot h_{2}}\right)
\end{aligned}
$$

Using the following compliance factors for the calculations:

$$
\begin{array}{ll}
\beta_{1}=\frac{12 \cdot E_{a} \cdot\left(1-v_{1}^{2}\right)}{E_{1} \cdot h_{1}^{3} \cdot t} & \beta_{2}=\frac{12 \cdot E_{a} \cdot\left(1-v_{2}^{2}\right)}{E_{2} \cdot h_{2}^{3} \cdot t} \\
\alpha_{1}=\frac{G_{a} \cdot\left(1-v_{1}^{2}\right)}{E_{1} \cdot h_{1} \cdot t} & \alpha_{2}=\frac{G_{a} \cdot\left(1-v_{2}^{2}\right)}{E_{2} \cdot h_{2} \cdot t}
\end{array}
$$

A.1.6 Oplinger method (1991)

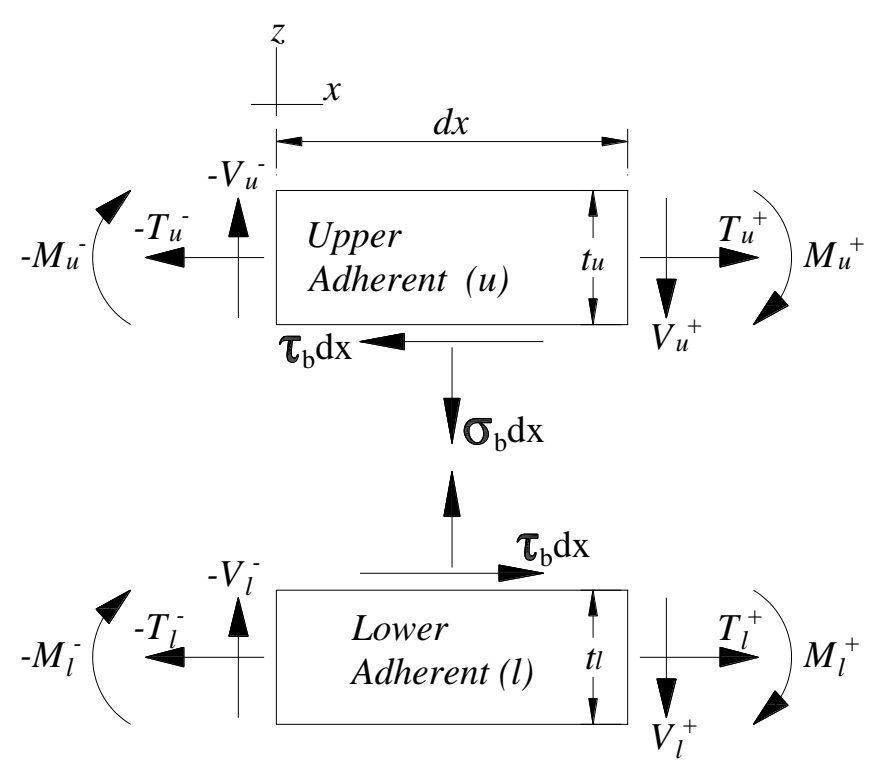

Fig. A 7 Single-lap joint geometry; Oplinger [11].

The formulas used to estimate the distribution of the shear stress; see Oplinger [11].

The parameters used to calculate the coefficient $k_{n}$, mentioned in Table 5 and enhanced for any thickness of adherents, are:

$$
\begin{array}{ll}
R=\sqrt{\frac{12 \cdot \sigma_{x} \cdot t_{b}}{G_{b} \cdot t}} & R_{1}=\frac{\sqrt{8 \cdot v_{1}}}{R} \\
v_{1}=a+b & v_{2}=a-b
\end{array}
$$




$$
\begin{aligned}
& a=4 \cdot\left(1+\frac{3}{4} \cdot \rho_{t}\right)+\frac{R^{2}}{4} \quad b=\sqrt{a^{2}-R^{2}} \\
& u_{1}=\frac{R_{1} \cdot R \cdot \beta}{\sqrt{8}} \quad u_{2}=\sqrt{8} \cdot R_{2} \cdot \beta \\
& \beta=\sqrt{\frac{\rho_{G}}{\rho_{t}}} \quad \rho_{t}=\frac{t_{b}}{t} \quad \sigma_{x}=\frac{T}{t_{b}}
\end{aligned}
$$

$(18 \mathrm{e})$

with

$$
\begin{aligned}
C_{1}=\frac{J_{1}}{64 \cdot J_{2}} & C_{2}=\frac{1}{48 \cdot J_{2}} \\
J_{1}=\frac{1}{R_{2}{ }^{2}-\frac{R^{2}}{16}} & J_{2}=\frac{R_{2}^{2}}{4 R_{2}^{2}-1}
\end{aligned}
$$

For adhesive thicknesses much greater than the thickness of the adhesive $\left(t>>t_{b}\right)$, the coefficient $k_{n}$ can be simplified to:

$$
k_{n}=\frac{1}{1+\sqrt{8} \cdot \frac{T_{h 22}}{T_{h 1}}}
$$

Where

$$
T_{h 1}=\tanh \left(U \cdot \lambda_{0}\right) \quad T_{h 21}=\tanh \left(\frac{u_{1} \cdot \lambda}{2}\right) \quad T_{h 22}=\tanh \left(\frac{u_{2} \cdot \lambda}{2}\right)
$$

(21)

The necessary parameters to estimate the effective adhesive length, mentioned in Table 4, are:

$$
\begin{aligned}
& \Lambda^{4}=t_{u}{ }^{4} \cdot \frac{K_{b}}{4} \cdot\left[\frac{1}{D_{u}}+\frac{1}{D_{l}}\right] \\
& \lambda^{2}=t_{u}{ }^{2} \cdot \frac{K_{b}}{2 \cdot C_{v}} \cdot\left[\frac{1}{B_{u}}+\frac{1}{B_{l}}+\frac{t_{u}{ }^{2}}{4 \cdot D_{u}}+\frac{t_{l}{ }^{2}}{4 \cdot D_{l}}\right] \\
& K_{b}=\frac{E_{b}}{t_{b}} \quad C_{v}=\frac{E_{b}}{2 \cdot G_{b}}=1+v_{b} \\
& B_{u}=\frac{E_{u} \cdot t_{u}}{1-v_{u}{ }^{2}} \quad B_{l}=\frac{E_{l} \cdot t_{l}}{1-v_{l}{ }^{2}}
\end{aligned}
$$




$$
D_{u}=\frac{E_{u} \cdot t_{u}^{3}}{12 \cdot\left(1-v_{u}^{2}\right)} \quad D_{l}=\frac{E_{l} \cdot t_{l}^{3}}{12 \cdot\left(1-v_{l}^{2}\right)}
$$

A.1.7 Zou method (2004)

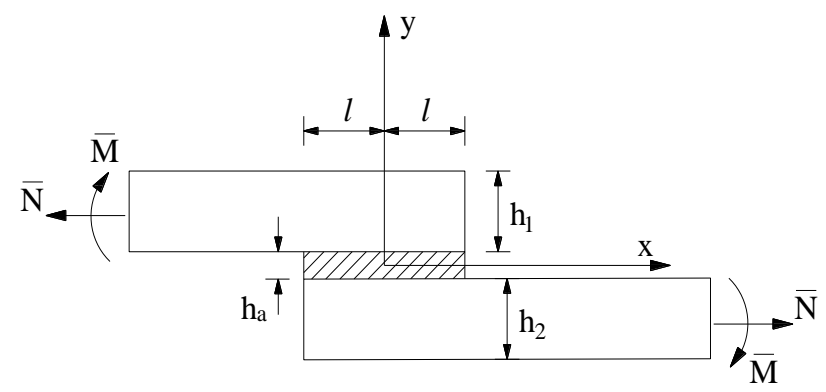

Fig. A 8 Single-lap joint diagram proposed by Zou [12]

The formulas used to estimate the shear and normal stress; see Zou [12].

\section{A.2 Implicit Methods}

\section{A.2.1 Renton and Vinson method (1973)}

Renton and Vinson [13] developed a system of equations that allow the estimation of the adhesive normal shear stresses of a balanced or unbalanced single joint, considering the adherent material as anisotropic composite and the adhesive as isotropic. The methodology is based on the method developed by Goland and Reissner [6], who used the theory of linear behaviour to estimate the loads at the endpoints and solved an ordinary linear differential equation of the eighth order to estimate the shear and normal stresses. In addition, the method performs experimental tests of tension and fatigue to determine the behaviour of the failures in the laminate of the single-lap joint.

Renton and Vinson [13] recommend:

- To reduce stress peaks, care must be taken to maintain a similar planar stiffness of the adherents.

- A single joint is more efficient if the elasticity modulus of the adhesive is smaller than the elasticity modulus of the adherents.

- The adhesive failure is independent of the length of the adhesive and is very little related to the thickness of the adhesive.

- The strength of the joint can be improved by increasing the thickness of the adhesive at its ends.

\section{A.2.2 Ojalvo method (1977)}

Ojalvo [14] focused on analysing the influence of the adhesive thickness on the estimation of the shear and normal stresses. His research was based on the approach of Goland and Reissner, but he modified the differential equation and used three assumptions related to the behaviour of the single joint to define the methodology. Finally, he concluded that the thickness of the adhesive is important in the estimation of the stresses, mainly for the maximum values that are generated at its ends because when the effect of the adhesive thickness is included in the calculations, the shear stress increases and the normal stress decreases. 


\section{A.2.3 Delale method (1981)}

Delale [15] developed a methodology for single-lap joints of the balanced adherents. This methodology is applied for linear-elastic analyses, considering [15]:

- The adherents are an orthotropic plate material and for their analysis, the transversal shear stresses are used.

- The adhesive is a linear-elastic material.

- The stress variation in the adhesive thickness direction is negligible.

- The deformations in the z-direction of adhesive are zero, and only coplanar deformations are considered.

\section{A.2.4 Adams and Mallick method (1992)}

Adams and Mallick [16] analysed a single joint subjected to thermal stress loads. This methodology is applied to non-balance adherents, in which the adhesive is considered as a unidirectional anisotropic material for non-linear analysis. The adherents are analysed as flexural plates, while the adhesive is a series of tension and shear springs. Beginning with the theory of two-dimensional elasticity, these authors developed implicit formulas for calculating tensile and normal stresses in the upper and lower parts of the adhesive. These formulas include the terms for the effects of bending, shear, and hydrothermal deformation in the adherent and adhesive.

\section{A.2.5 Tong method (1996)}

Tong [17] assumed in his investigation that the adhesive has a non-linear stress-strain behaviour while the adherents have linear-elastic behaviour. Normal and shear deformations in the adhesive are constant through the adhesive thickness. The adherent-adhesive-adherent sandwich model is used to predict the strength of the joint only for balanced adherents. This author also explains that the product of the deformation energy density and the thickness of the adhesive is equal to the energy release rate for fracture failure modes.

\section{A.2.6 Smeltzer method (2003)}

The method proposed by Smeltzer [18] allows an evaluation of the distribution of normal and shear forces along with the adhesive. In its analysis, this method considers the adherent plates as anisotropic and elastic-linear and the adhesive as isotropic nonlinear, elastic and plastic, behaving in a cylindrical form under a condition of flat deformation. This author presented both linear and non-linear examples and compared the results of his method to those of Goland and Reissner [12] and Bigwood and Crocombe [10] [30], obtaining lower maximum normal and shear stresses. 
A.3 Hull lengthening study case

Table A 1 Weights, centroids, and location for the calculation of still water moment

\begin{tabular}{|c|c|c|c|c|c|c|}
\hline \multirow[b]{2}{*}{ Item Name } & \multirow[b]{2}{*}{$\begin{array}{c}\text { Weight } \\
\text { ton }\end{array}$} & \multicolumn{3}{|c|}{ Longitudinal } & \multirow{2}{*}{$\begin{array}{c}\text { Transversal } \\
\text { Arm } \\
\mathrm{m}\end{array}$} & \multirow{2}{*}{$\begin{array}{c}\text { Vertical } \\
\text { Arm } \\
\mathrm{m}\end{array}$} \\
\hline & & $\begin{array}{c}\text { Arm } \\
\mathrm{m}\end{array}$ & $\begin{array}{l}\text { Aft Limit } \\
\text { m }\end{array}$ & $\begin{array}{l}\text { Fwd Limit } \\
\text { m }\end{array}$ & & \\
\hline Lightship & 40.577 & -2.004 & -2.004 & -2.004 & 0 & 2.609 \\
\hline Passengers + crew & 1.35 & -2.000 & -2.000 & -2.000 & 0 & 3.08 \\
\hline Fix. Ballast & 0 & -4.085 & -4.085 & -4.085 & 0 & -0.024 \\
\hline Tank grey water & 1.719 & 2.418 & & & 0 & 0.531 \\
\hline Tank DO PS & 3.131 & -4.015 & & & -1.257 & 1.195 \\
\hline Tank DO SB & 3.131 & -4.015 & & & 1.257 & 1.195 \\
\hline Tank FW Aft PS-Ballast & 1.554 & -12.743 & & & -1.391 & 1.013 \\
\hline Tank FW Aft SB-Ballast & 1.554 & -12.743 & & & 1.391 & 1.013 \\
\hline Tank Black \& Grey empty & 0 & 6.041 & & & 0 & 0.047 \\
\hline Tank FW PS & 2.854 & -10.529 & & & -1.437 & 0.968 \\
\hline Tank FW SB & 2.854 & -10.529 & & & 1.437 & 0.968 \\
\hline Tank black water & 1.877 & -1.375 & & & 0 & 0.509 \\
\hline TOTAL & 60.601 & -3.420 & & & $\mathbf{0}$ & 2.113 \\
\hline
\end{tabular}




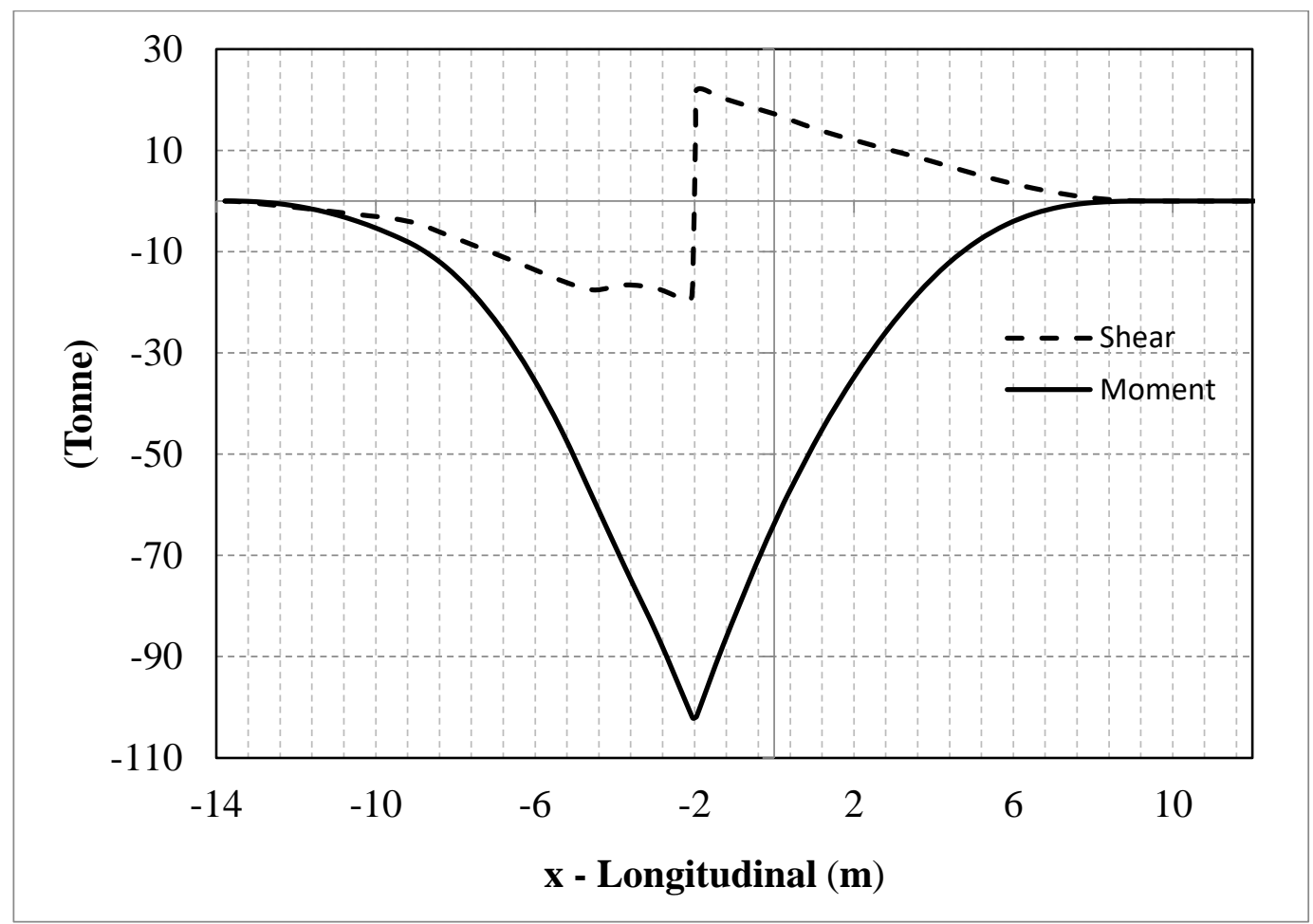

Fig. A 9: Moment and shear stress on still water for the diving ship

$\begin{array}{lll}\text { Submitted: } & \text { 26.04.2020. } & \text { Franklin Dominguez (the corresponding author), jdominguez@tecnavin.com } \\ & & \text { Doctoral Program, Universidade da Coruña, 15403 - Ferrol, Spain } \\ \text { Accepted: } & \text { 15.09.2020. } & \text { TECNAVIN S.A., Chimborazo 2912 y Garcia Goyena, 090114, Guayaquil, } \\ & \text { Ecuador. } \\ & \text { ESPOL Polytechnic University, Escuela Superior Politécnica del Litoral, } \\ & \text { ESPOL, Facultad de Ingeniería Marítima y Ciencias del Mar - FIMCM, } \\ & \text { Campus Gustavo Galindo Km. 30.5 Vía Perimetral, P.O. Box 09-01-5863, } \\ & \text { Guayaquil, Ecuador } \\ & \text { Luis Carral, lcarral@ @udc.es } \\ & \text { Department of Naval and Industrial Engineering, Universidade da Coruña, } \\ & \text { Campus Esteiro, } 15403 \text { - Ferrol, Spain }\end{array}$

